\title{
EdTech $^{\text {Hub }}$
}

Clear evidence, better decisions, more learning.

Technology, Teacher Professional Development and Low- and MiddleIncome Countries

Technical report on systematic mapping review

Date $\quad$ September 2021

$\begin{array}{llll}\text { Authors } & \text { Sara Hennessy } & \text { Sophia D'Angelo } & \text { Nora McIntyre } \\ & \text { Saalim Koomar } & \text { Adam Kreimeia } & \text { Lydia Cao } \\ & \text { Meaghan Brugha } & \text { Asma Zubairi } & \end{array}$
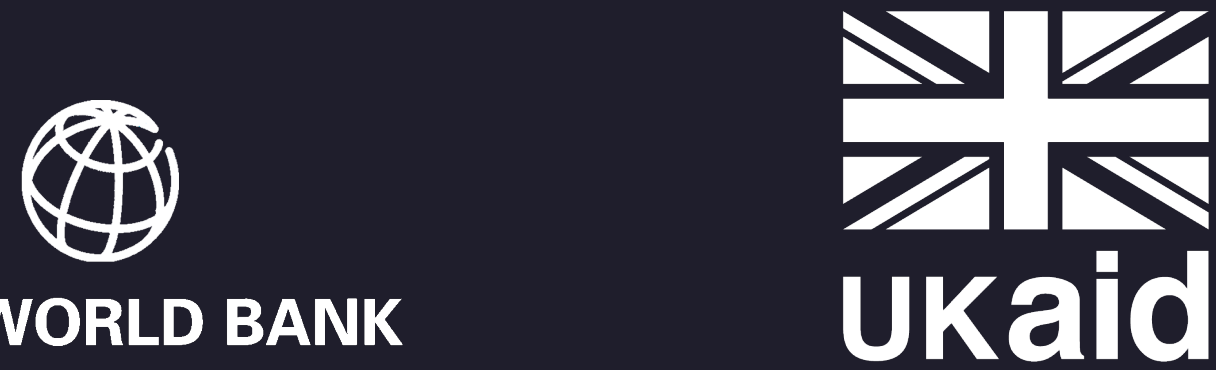

THE WORLD BANK 


\section{About this document}

\section{Recommended citation}

Licence

\section{Reviewers}

\section{Acknowledgements}

Hennessy, S., D'Angelo, S., Mclntyre, N., Koomar, S., Kreimeia, A., Cao, L., Brugha, M., Zubairi, A. (2021). Technology, Teacher Professional Development and Low- and Middle-Income Countries: Technical report on systematic mapping review. Technical Report. https://doi.org/10.53832/edtechhub.0047. Available at https://docs.edtechhub.org/lib/VTQDT65R. Available under Creative Commons Attribution 4.0 International, https://creativecommons.org/licenses/by/4.0/.

Creative Commons Attribution 4.0 International https://creativecommons.org/licenses/by/4.0/ You - dear readers - are free to share (copy and redistribute the material in any medium or format) and adapt (remix, transform, and build upon the material) for any purpose, even commercially. You must give appropriate credit, provide a link to the license, and indicate if changes were made. You may do so in any reasonable manner, but not in any way that suggests the licensor endorses you or your use.

Caitlin Moss Coflan, Dick Ng'ambi

Note that the Introduction and Conclusion sections draw heavily from two previous outputs by EdTech Hub teams: Problem Analysis and Focus of EdTech Hub's Work (^Hennessy et al., 2021), and an internal position paper preceding this review that likewise focused on teacher professional development, educational technology and LMICs. 


\section{Summary}

Pre-service education and in-service teacher professional development (collectively defined as TPD) can play a pivotal role in raising teaching quality and, therefore, learning outcomes for children and young people in low- and middle-income countries (LMICs). However, TPD opportunities in LMICs are often limited, unevidenced, and unsustained, with mixed outcomes. Educational technologies offer potential to enhance formal and informal models of TPD. We present the first systematic mapping review of the literature pertaining to TPD and technology use in LMICs. The aim was to characterise appropriate and effective uses of technology. Three core research questions examined leverage of educational technologies in three ways:

- technology use in TPD (RQ1);

- teacher learning about / with technology that supports teaching, planning, and assessment practices (RQ2);

- teacher learning about / with technology that supports student learning (RQ3).

Our review yielded 265 studies spanning diverse geographies, learning environments, and TPD audiences. These studies were thematically coded to identify - among other characteristics - key design features of the TPD models, the tech devices and resources used, the intended outcomes, and contextual factors shaping the effectiveness, scalability, or sustainability of these approaches. The purpose of this technical report is to summarise key patterns among the studies reviewed and to identify key evidence gaps in order to push forward the agenda on improving teaching quality in LMICs.

Our results suggest that the volume of publications increased dramatically over the review period (2008-2020), indicating that the field is rapidly developing. Nevertheless, the review highlights various methodological and design-related evidence gaps, summarised in the conclusion of this report. They include the limited number of studies that focus on the needs of marginalised teachers and learners, and the lack of longitudinal studies that assess the sustainability of TPD outcomes. There is also a lacuna of research evaluating the impact of TPD on teaching practices and student learning outcomes. More research is needed to foster equitable and quality education systems for the most vulnerable countries and communities. The comprehensive, open database — including fine-grained thematic 
coding and quality assessment — offers a unique resource for the field. It can be used to support targeted inquiries by other researchers and stakeholders, and further work towards filling the evidence gaps identified. 


\section{Contents}

$\begin{array}{ll}\text { 1. Introduction } & 8\end{array}$

2. Literature Review 11

2.1. EdTech for teacher development 11

2.2. EdTech for teaching 11

2.3. Teacher support for EdTech use by learners 12

3. Method 13

3.1. Literature search $\quad 15$

3.2. Data synthesis 18

3.3. Quality scoring 19

3.4. Limitations 20

4. Results from data extraction: literature mapping across the field 21

$\begin{array}{ll}\text { 4.1. Number of publications per year } & 21\end{array}$

4.2. Publication types and authorship 22

4.3. Research designs of included studies $\quad 24$

5. Results from thematic coding: characteristics of the TPD studies 31

5.1. Studies by research question 31

5.2. Regional distribution 31

5.3. TPD settings and audiences 32

5.4. TPD designs and modalities 37

5.5. Technological devices and resources $\quad 40$

5.6. Identifying and measuring TPD outcomes 43

5.7. Factors shaping the effectiveness of TPD 46

5.8. TPD for marginalised learners 48

6. Conclusion $\quad 49$

7. References 51

Supplementary material $\quad 57$

$\begin{array}{ll}\text { Appendices } & 58\end{array}$ 
Appendix A. Low- and middle-income countries included in searches 58

Appendix B. Data extraction variables 58

Appendix C. Thematic coding scheme with RQ1-RQ3 frequencies 58

Appendix D. Research quality scoring framework 59

Appendix E. Number of studies by country 59

Appendix F. Number of studies by country income level 63 


\section{Abbreviations and acronyms}

$\begin{array}{ll}\text { DBR } & \text { design-based research } \\ \text { EiE } & \text { education in emergencies } \\ \text { HIC } & \text { high-income country } \\ \text { LIC } & \text { low-income country } \\ \text { LMIC } & \text { low- and middle-income country } \\ \text { MIC } & \text { middle-income country } \\ \text { OER } & \text { open educational resources } \\ \text { SDC } & \text { Sustainable Development Goal } \\ \text { SSA } & \text { sub-Saharan Africa } \\ \text { TPD } & \text { (pre-service and in-service) teacher professional } \\ & \text { development }\end{array}$




\section{Introduction}

Teachers can play a pivotal role in addressing the global learning crisis (^World Bank, 2018). In many low- and middle-income countries (LMICs), teachers are often under-qualified and lack access to professional development opportunities, compromising both pedagogical and subject knowledge. Where opportunities exist, the input is often too theoretical, not linked with practical classroom application, nor sustained over time. Vast numbers of learners, especially those in marginalised population groups, endure a poor quality educational experience culminating in under-achievement and limited life chances. Consequently, the $\uparrow$ Education Commission (2019) report on transforming the education workforce states that:

"Teacher quality is the most important determinant of learning outcomes at the school level, but in many countries teachers are in short supply, isolated, and not supported to provide effective teaching and learning" (p.6).

This underlines the significance of teachers in the learning process.

Sustainable Development Goal (SDG) target 4.1 aims to "ensure that all girls and boys complete free, equitable and quality primary and secondary education leading to relevant and effective learning outcomes" ( SDG-Education 2030 Steering Committee, no date). Yet children's learning in many LMICs - as evidenced by literacy and numeracy rates has remained stagnant or fallen below expected levels (^World Bank, 2018). According to estimates by the UNESCO Institute for Statistics (UIS) (^UIS, 2017), more than 380 million children worldwide (56\% on average and $85 \%$ in sub-Saharan Africa) will finish primary school without being able to read or do basic mathematics. Those learners furthest behind are often the most marginalised, including girls, children, and adolescents from poorer households, rural and remote communities, and ethnic and linguistic minorities, as well as refugee and displaced young people or learners with disabilities. Achieving substantial improvements and reducing learning inequalities are specific indicators for SDG4 Targets 4.1, 4.6, and 4.7. The work of EdTech Hub explores the role that educational technology (EdTech) use can play in reaching SDC 4 and these targets in particular, taking a systems approach in the process.

Teachers are a central part of this systems approach. In every country, teachers are critical to improving outcomes for marginalised learners. 
Teacher education and development are thus pivotal aspects of education systems, as enshrined in a key aim in the PDFID (2018) Education Policy to "overhaul outdated models of teacher training, drawing on evidence-based approaches to improve teachers' skills which deliver for children, including those who are poor and marginalised" (p.16). In both high-income and low-income countries the impacts of teacher development have nevertheless been mixed to date, owing to a range of contextual factors ( $\hat{\text { i }}$ McAleavy, et al., 2018; ^World Bank, 2018). However recent work indicates that the need for teacher development increases with the introduction of EdTech. For instance, the Hub's Rapid Evidence Review on personalised learning indicates that learning gains from personalised, adaptive technology use are greater when an experienced teacher is available to offer contextualised input and feedback ( $\$$ Major \& Francis, 2020). A meta-analysis of 77 randomised experiments by $\uparrow$ McEwan (2015) found that the two features of school-based interventions associated with the largest effect sizes for learning in LIC primary schools were use of EdTech $(0.15)$ and teacher training (0.12). These need to go hand in hand; it is now widely recognised that technology by itself has no agency - impact depends on how it is used by educators and learners. We posit that quality teacher development effectively supported by EdTech use could have huge potential to impact on student learning.

Accordingly, one of EdTech Hub's five overarching themes is Robust research on the use of technology to improve teacher professional development. In this review we use the term 'teacher professional development' (TPD) as shorthand to encompass a broad focus on formal

\section{programmes and informal peer learning of both pre-service and in-service teachers at school level in LMICs.}

Research questions (RQs) for the review covered TPD both for and with technology use related to teaching and student learning. They are:

RQ1. How can the use of technology support TPD in LMICs, including improving subject knowledge and / or classroom pedagogy? ('Tech for TPD')

RQ2. How can TPD support teaching, lesson planning, and assessment using technology in LMICs? ('Tech for teaching')

RQ3. How can TPD help teachers to support effective use of technology by learners in LMICs? ('Tech for student learning')

We provide a brief literature review for each of the RQs in Section 2, and then outline our methodology in Section 3. The RQs were addressed at a 
high level of abstraction suitable for a systematic mapping review (^Kitchenham et al., 2009), including descriptive questions such as:

- What empirical methods (e.g., quantitative, qualitative, mixed methods) and methodologies (e.g., case study, action research, ethnography) have been used?

- What characteristics describe the sample of teacher participants for these studies (e.g., size of sample, teacher age and experience)?

- What tools (e.g., interviews, in-person or video observations, focus groups) were used to collect data from research participants?

- In which LMICs has research been concentrated?

- What technologies and modes of TPD have been used, promoting what TPD outcomes?

- Which subjects and grades do the TPD initiatives address?

- Are the TPD initiatives designed to support certain groups of students who are marginalised (e.g., learners with disabilities, girls, displaced children) and, if so, which groups?

These questions - and others - are answered in Sections 4 and 5 of this report. Section 4 draws on data extraction methods to summarise key methodological approaches and research designs, while Section 5 draws on the thematic coding to synthesise key design features of the TPD models researched. In Section 6 we summarise the key evidence gaps in order to encourage future researchers to continue mobilising the creation and dissemination of knowledge on technology and TPD in LMICs. 


\section{Literature Review}

\subsection{EdTech for teacher development}

The use of EdTech to improve teacher education and professional development processes (RQ1) is a wide-ranging category. The use of videos for teachers to observe model teachers or watch themselves and critically reflect on teaching practices is one common area of research within this category (e.g., iKaneko-Marques, 2015; ^Hennessy et al., 2016; ^ Lok et al., 2018); nevertheless, evidence from low- and middle-income countries (LMICs) is inconclusive ( Major and Watson, 2017). Preloaded devices often used to provide teachers with teaching and learning materials and lesson plans - are also a common EdTech tool to support teacher learning ( $\uparrow$ School-to-School International (STS), 2017; ^Gloria \& Oluwadara, 2016); less common in the literature are TPD models that use these devices to support coaches and mentors, but there are some promising initiatives (:Piper et al., 2017). Video calls for remote coaching and mentoring have also been found to be a cost-effective approach — especially in providing TPD for teachers in remote and rural regions ( $\Uparrow$ Nedungadi et al., 2018) though there is mixed evidence around the sustainability of these models (e.g. ^Cilliers et al., 2020). Text messages (i.e. SMS), online forums, and social media - especially Facebook or WhatsApp - are an increasingly popular EdTech resource to support teacher collaboration, foster remote communities of practice, or prompt and reinforce new pedagogies ( $\$ S l a d e$ et al., 2018). Teachers are a diverse group, with varying interests and levels of confidence and skill in terms of technology use, pedagogy and content knowledge. The effectiveness of TPD models that leverage EdTech for teacher learning is therefore determined by how well they are aligned to the needs and interests of the teachers they seek to serve.

\subsection{EdTech for teaching}

This area refers to developing teachers' use of EdTech to support their planning, classroom-level assessment, and evaluation related to classroom teaching and learning (RQ2). Using technology to develop lesson planning is a prime example. For example, mobile phones can support teaching through communication during lesson planning, by relating subject knowledge to authentic locations and activities during teaching, and with image and data capture to support assessment and post-lesson reflection ( EEkanayake and Wishart, 2014). Teachers frequently use internet sources and social media or online forums to develop lesson structure, content, and 
activities. Communities of practice (such as the $\uparrow$ Teachers' Research Exchange, for example) can form part of TPD initiatives in which teachers share ideas and resources around lesson planning. However, these communities have been examined primarily in relation to higher education practice and research, with a gap concerning teacher development initiatives at lower levels. There is an unexplored tension between scaffolding to improve teaching quality and constraining adaptability when using scripted lessons.

\subsection{Teacher support for EdTech use by learners}

How can improved TPD support learners' use of EdTech (a mobile application, for instance) in classrooms in LMICs (RQ3)? This question is relatively under-researched, especially in LMICs, and therefore warrants further investigation. This may include, for example, exploring the extent to which TPD initiatives incorporate opportunities for experimentation and rehearsal with new technology ( McAleavy, et al., 2018) so as to develop skills and confidence in using it with learners in classrooms (as in the OER4Schools workshops: ^Hennessy, et al., 2016), and if this is not feasible, how it is mitigated (for example, through use of exemplar videos). Critical examination during TPD of issues and policies around child protection, data and privacy rights, and cultural sensitivity when using technology in the classroom is also required. Finally, it is striking that very little of the research on EdTech use in TPD in LMICs supports adaptation to either learning levels (personalised learning) or marginalised learners' needs. 


\section{Method}

The review was conducted in two phases, offering complementary insights at different levels of granularity. First, we undertook a systematic mapping review. The Preferred Reporting Items for Systematic Reviews and Meta-Analysis (PRISMA) methodology (^Moher et al., 2009) employed involved two rounds of screening against a set of inclusion criteria followed by in-depth thematic coding along with data extraction, to provide a holistic overview of the whole research field (use of EdTech related to teacher learning in low- and middle-income countries [LMICs]: RQ1-RQ3). A systematic map differs from a conventional systematic review since it need not be driven by a particular research question but reviews a broader topic (iKitchenham et al., 2009); it may not involve quality assessment; and it results in a minimal narrative with a tabular summary of studies (^Grant \& Booth, 2009). Such a review can inform a decision about whether to undertake in-depth review and synthesis of all of the studies or just a subset. We subsequently focused on the most prominent set emerging: EdTech use as a medium for teacher learning (RQ1).

Phase 2 entailed an in-depth conventional systematic review of this literature, including appraising its quality and synthesising the findings from the research evidence (^ibid; ^Moher et al., 2009). This two-stage combination of review methods offered a unique contribution to the field; the initial wide net in Phase 1 yielded an extensive database whose coding identified prominent themes and gaps in the field; and the deep dive in Phase 2 offered detailed insights into those themes and gaps, with quality assessment allowing the higher quality research studies to be prioritised. This report is on the mapping review in Phase 1, with the systematic literature review in Phase 2 reported separately ( $\uparrow$ Hennessy et al., Forthcoming). The overall review process of eight steps, from defining the review scope to selecting the final papers for analysis in Phase 2, is illustrated in Figure 1.

Three elements of the methodology - screening, thematic coding and quality scoring - were carried out by 3-5 researchers, each handling a subset of the data. The fourth element - data extraction — was conducted by a single team member. In each case, an extensive training and calibration period (lasting several weeks) preceded data processing, whereby researchers familiarised themselves with the relevant scheme (inclusion / exclusion criteria in screening, coding scheme, quality scoring framework, data extraction variables) and contributed to its development through pilot testing and discussion. In this stage, blind parallel processing of the same papers by team members facilitated close alignment between 
them and iteratively eliminated any ambiguities within the schemes.

During this stage and subsequently, all questionable cases were resolved through discussion among the team and consultation of the lead author where appropriate. Ongoing calibration between team members was ensured through regular spot checks involving blind screening, coding, or scoring of the same records, before moving on to the next round of the process.

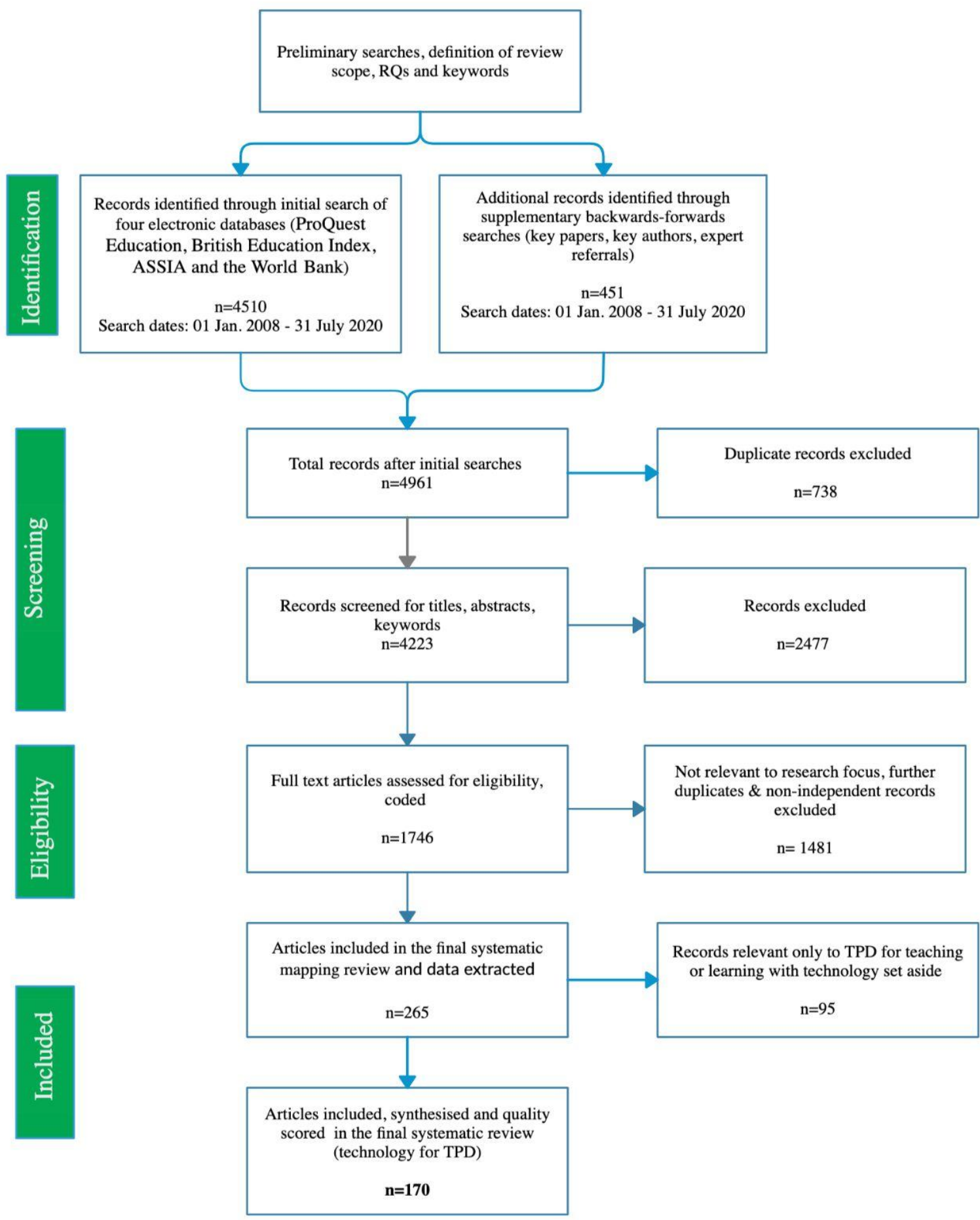

Figure 1. PRISMA diagram 


\subsection{Literature search}

\subsubsection{Search strategy}

The focus of our systematic mapping review was teacher professional development and learning through and for EdTech use in school-level education in LMICs (Figure 2). A provisional a priori set of associated key terms generated by the team (based on knowledge of the literature in the field) was trialled and iteratively refined through a series of preliminary searches using ProQuest.

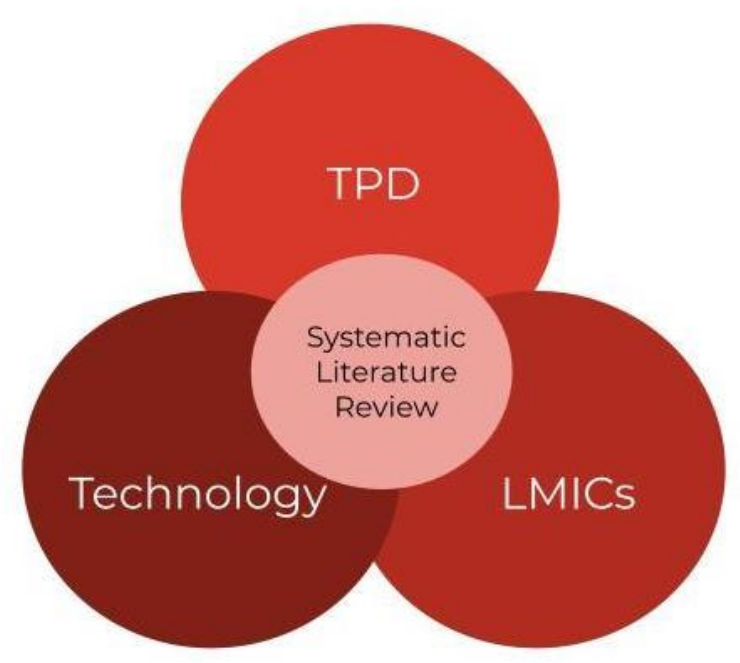

Figure 2. Intersecting target search areas

The resulting search terms are listed in Table 1. These were applied to locate academic and grey literature from four electronic databases: ProQuest Education, British Education Index, Applied Social Sciences Index \& Abstracts (ASSIA), and the World Bank. Supplementary searches comprised backward-forward searching (using Google Scholar, based on seeking papers by eight key authors in the field) and a snowballing technique to identify references from seminal literature reviews in the field. These searches collectively yielded 204 papers, of which 10 were independent, met the inclusion criteria, and were included. We also contacted 11 experts in the field, largely nominated by the first author, and 7 responded with a total of 75 recommended sources, of which 15 were independent, met the inclusion criteria and were included in the mapping review. (Note: both the expert referrals and the supplementary searches included many relevant papers that duplicated the initial search outcomes and were therefore discounted). 


\section{Theme no. Theme name Search terms}

1 LMIC LMIC OR low middle income countr* OR
sub*saharan africa OR latin america
OR
[Actual LMICs fully listed]

2

TPD

teacher development OR teacher training OR teacher education OR teacher learning OR teacher professional learning OR

[teacher OR educator OR classroom practitioner OR school OR instructor] AND [professional development OR in*service training OR pre*service training OR in*service education OR pre*service education OR coach* OR mentor*]

technolog* OR digital OR device OR software OR hardware OR phone OR ICT OR comput* OR video OR radio OR TV OR televis* OR laptop OR tablet OR learner management system OR LMS OR virtual learning environment OR VLE OR e*learning OR blended learning OR online learning OR mobile learning OR social network* OR messenger OR messag* OR SMS OR MOOC OR social media OR professional learning network OR remote learning OR distance learning

\subsubsection{Eligibility screening}

In correspondence with this review's focus, our eligibility criteria comprised three thematic foci.

\section{Theme 1}

Studies were included if they collected data from at least one low- and / or middle-income country listed in the World Bank's (2020) country inventory

\footnotetext{
'The use of an asterisk (*) denotes a wild character used to locate all singular/plural forms of a term.
} 
(^World Bank, 2021). The search thereby spanned a range of 136 countries in sub-Saharan Africa (SSA), South Asia, Latin America and the Caribbean, Middle East and North Africa, East Asia and the Pacific, and Europe and Central Asia (listed in Appendix A).

\section{Theme 2}

Studies were included if they investigated teacher learning - i.e., teacher education, teacher professional development, mentoring or coaching, or peer learning initiatives. Some focus on teacher learning that was linked to technology use was required, including situational and contextual factors influencing teacher learning through or for using technology, skills and substantive knowledge, and technology to motivate teachers in their own learning. Excluded were studies that only reported (without any link to some form of teacher education / learning) teachers' attitudes, beliefs or perceptions in relation to technology, their self-efficacy, digital skills, approach to technology use, intention or readiness to use technology, or snapshot assessments of knowledge about how to use technology.

\section{Theme 3}

Technology used for teaching and learning - teacher development / learning, lesson planning, and assessment, or for student learning (e.g., devices such as video, tablets, or phones and / or digital media, software, and teaching / learning resources). Low-tech devices like non-digital radio and television were also included since these are often the only available technologies in remote rural areas. Excluded was technology for educational management (e.g., data systems, registration software, emails to parents).

Additional eligibility criteria included:

- Literature published in English (2008-2020, with a cut-off date of 31 July 2020);

- Empirical investigations, including primary and secondary data, excluding reviews and papers that are primarily narrative or theoretical in nature;

- Peer-reviewed academic journal articles, books and book chapters, PhD theses, peer-reviewed conference papers, grey literature (excluding blogs and very short briefing reports); 
- Pre-service and in-service teachers of students aged 3-18, including teaching assistants but excluding school leaders when researched alone without an accompanying focus teachers;

- Formal taught programmes, workshops, or informal education / learning taking place on- or off-site (e.g., in government / private schools, teacher training colleges, district / community centres), including through peer communication and support (e.g., via online communities of practice).

In Stage 1, titles, abstracts and keywords were screened by three authors to exclude irrelevant texts. In Stage 2, full texts were read by three authors to exclude further records. Duplicate and non-independent records were eliminated. Journal articles were prioritised over other sources such as book chapters and conference papers reporting the same study. Eligibility screening was carried out in an open-source, dedicated, systematic review platform, $\uparrow$ Colandr.

\subsection{Data synthesis}

Data extraction and thematic categorisations were conducted in $\uparrow$ Colandr.

\subsubsection{Data extraction}

Data extraction was conducted by one author after iterative pilot testing and refinement of the framework by three authors. Owing to the wide diversity of settings within reviews of research in international development, and the consequent challenges in determining relevance and generalisability of findings across a range of different populations and 'real world' contexts ( $\$$ Waddington et al., 2012), we paid particular attention to describing contextual characteristics in detail.

The final terms included: publication type, TPD audience, TPD setting (type of institution, country), sampling strategy, sample size, clustering basis if applicable (e.g., teaching experience), teacher age and gender, study design, qualitative data sources, quantitative data sources, and data analytic techniques. A brief summary of findings from each study was formulated at the same time. See Appendix B for details.

\subsubsection{Thematic coding}

Thematic coding of the studies consisted of the broad application of established qualitative approaches to textual coding ( $i$ Belotto, 2018) through careful reading and annotation of full texts by three authors. The 
substantive expertise among the authors was harnessed to develop a draft, a priori, thematic framework with high potential for applicability to the studies. The framework was then tested on increasing 'sample sizes' of the studies. During the first iteration, ten studies were coded using this framework, which was amended and augmented before being applied to update the same studies and ten more. Between each new cycle, potential changes and 'emerging codes' were logged for whole-team discussion and agreement. This iterative framework development process took place over four cycles. Coding of all studies was then finalised during the fifth cycle (producing the framework detailed in Appendix C) before exporting thematic data for the whole database of studies.

The framework included: TPD audience, Education Level, TPD context, Subject, Tech devices, Tech resources, Tech for communication, TPD modes and methods, TPD design, TPD peer support, TPD outcomes, Factors at system level, Factors at local level, Marginalised learners, Review research questions. Cross-tabulations were carried out to explore key relationships of interest.

\subsection{Quality scoring}

As a precursor for the subsequent synthesis of findings in the Phase 2 systematic review, studies addressing RQ1 (the 'Tech for TPD' theme) underwent quality assessment. This process used a criteria checklist iteratively developed with colleagues across our wider research programme (EdTech Hub), drawing in particular on the Building Evidence in Education ( $\left.\mathrm{BE}^{2}\right)$ ( $($ Hinton \& Robinson, 2015) and Mixed Methods Appraisal

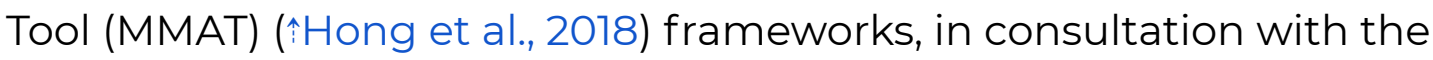
Research Quality Plus framework for international development research ( MacLean \& Sen, 2018). As a result, six dimensions were considered and iteratively refined until a final version was reached and systematically applied across the dataset by five researchers. The six final dimensions include research conceptualisation, contextual components, research design, methodological bias, methodological sensitivity to culture, and claims and conclusions (see Appendix D for a copy of the full tool). One of the dimensions (research design) was double-weighted due to its particular importance in shaping the academic rigour of the evidence.

Each record was awarded a total of up to 21 and banded into four rating categories ( 1 = Low, 2 = Low medium, 3 = Medium high, $4=$ High) for the purpose of synthesis. Note that although the quality assessment framework is pioneering in its holistic nature, a limitation of this tool is that shorter publications, such as conference papers, unfortunately score less 
highly than extended reports such as journal publications and that journal publications may limit word lengths or specify the sections to be included in manuscripts and therefore some sections (e.g. ethics) may likely be excluded from these records, affecting the scores they received.

\subsection{Limitations}

A major limitation of the review is that it focused only on publications in English. This is a common limitation in systematic reviews, which often appear to favour publications from English-speaking researchers in high-income countries (HICs) ( $\uparrow A l e x a n d e r, 2020$ ). Future studies could include publications in more languages, which would also allow for the dissemination of knowledge from less represented countries and researchers from LMICs. The cut-off date for literature screening meant that the review also does not cover published works pertaining to the Covid-19 context that began in Spring 2020. 


\section{Results from data extraction: literature mapping across the field}

The results narrative in this report provides descriptive statistics of the literature emerging ( $n=265$ sources), highlighting key methodological trends and patterns across all three of our research questions. RQ1, which focuses on 'technology for teacher learning in LMICs' ( $n=170$ ), emerged as the most common focus of inquiry in the studies collected (64\% of studies). $\mathrm{RQ1}$ is examined in more depth in the forthcoming journal article that synthesises findings from the systematic literature review (^Hennessy et al., Forthcoming). Since further in-depth analyses relating to RQ1 (exploring interactions between key variables) were completed for that review, some sections within the results presented here also provide a close-up of trends emerging from that specific literature. The next most prevalent focus was studies addressing RQ2 ('tech for teaching', a focus of 111 studies). RQ3 ('tech for student learning') was a focus in 57 studies.

\subsection{Number of publications per year}

This systematic review found that from 2012 onwards the number of studies on tech for TPD in LMICs has increased significantly (Figure 3). The figures confirm that the choice of the 12-year time period captured the development of the field almost from its infancy; the field is at an early stage compared to research on TPD without technology mediation and research on other uses of EdTech. In each of the past five years, for example, at least 30 studies have been published, compared to just 12 studies that were published a decade ago. It is important to note that the studies were collected until July 2020, and therefore the number of studies in 2020 will not be representative of all those published that year. As stated in Section 3, the review does not capture the explosion of research on EdTech for remote teaching and learning during Covid-19. Overall, the proliferation of research and gradual increase over time shows that EdTech for TPD in LMICs is an emerging - and increasingly relevant - field. 


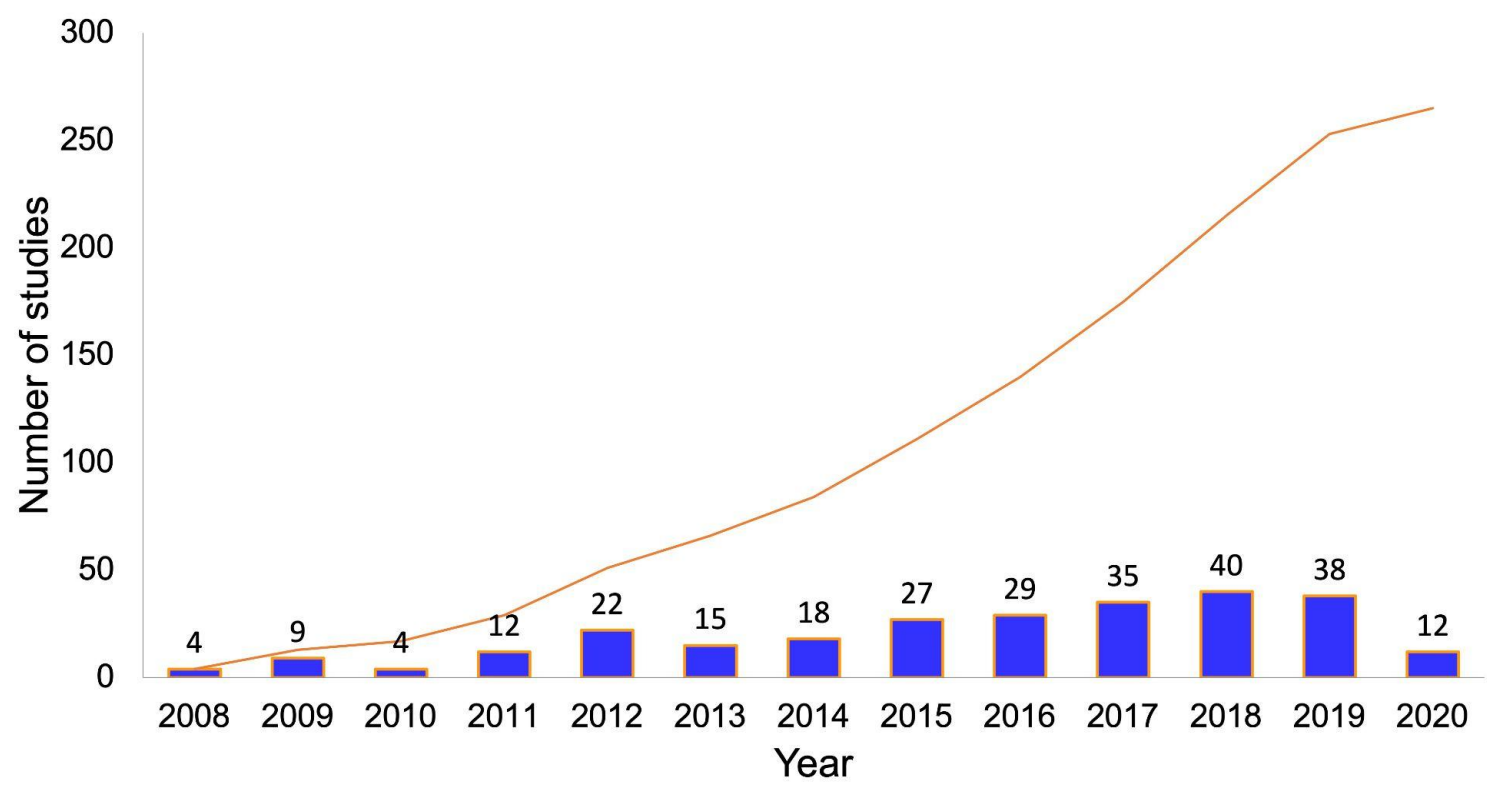

-Number of studies by year $\quad$-Number of studies

Figure 3. Number of publications per year from January 2008-July 2020

\subsection{Publication types and authorship}

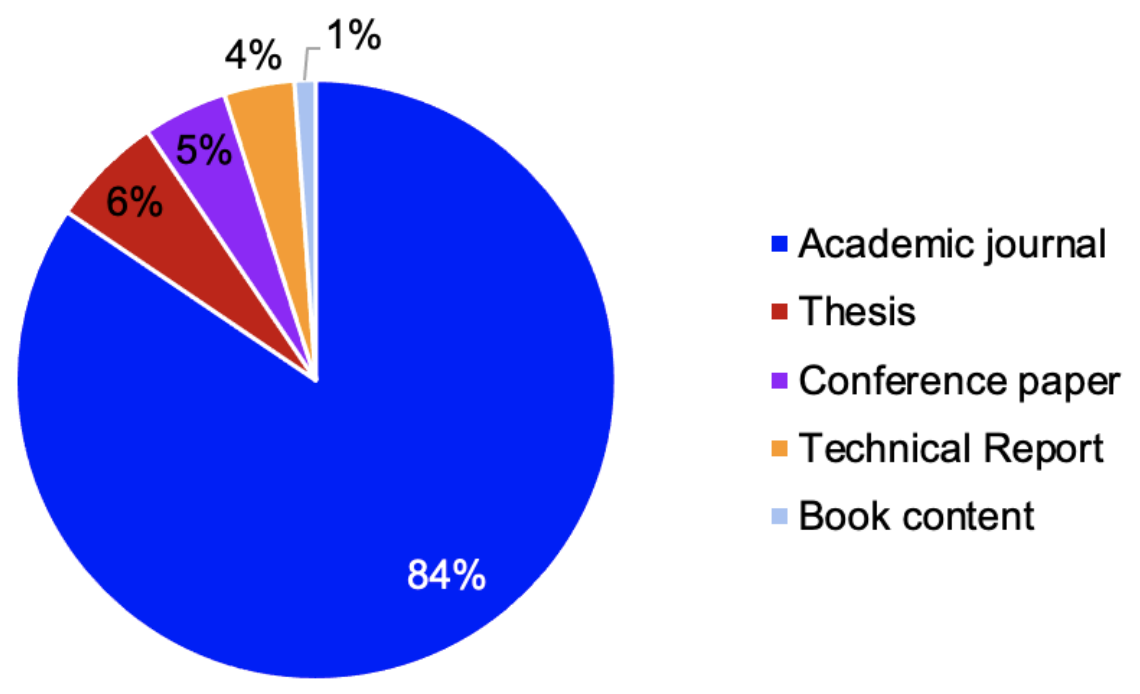

Figure 4. Distribution of publication types

Figure 4 shows that an overwhelming majority of the studies emerging in Phase 1 were published via academic journals, although journal quality varies significantly. Non-academic publications, such as technical reports, made up a minuscule proportion (4\%). As our search criteria included grey literature, this finding is surprising. During our initial search, we experienced difficulties in gaining access to reports. It is unclear whether 
they did not exist or are publicly unavailable; publication of reports to sponsors is often prohibited, however.

There was a very wide spread of authors. The 12 most prolific authors across the field are listed in Table 2; each (co-)authored at least three papers. Six of these authors are based in LMICs.

Table 2. Most prolific authors in the database

\section{Author name}

Voogt, Joke

Wolfenden, Freda

Agyei, Douglas, D.

Hennessy, Sara

Onguko, Brown

Tanzania

Kenya

Kenya

Bangladesh

Turkey

Aydin, Belgin

Turkey

Netherlands

Tanzania

Kafyulilo, Ayoub

Tanzania

Tanzania

Kwayumba, Dunston

Kenya

Kenya

3

Yan, Hanbing

China

China
3 3 3

5

4

4

4

4

4 


\subsection{Research designs of included studies}

The findings in this section derive from the data extraction described in 3.2.1. They consider which research designs, samples, data collection, and analysis methods are applied to examine teacher learning through and for technology use.

It is important to highlight that since a single variable may contain more than one code, the percentages displayed in the figures depict the proportions of each code out of the total numbers of codes applied rather than the total numbers of studies. For example, a single study could have used multiple sampling strategies (e.g., purposive and volunteer); as a result, it would have two codes under the variable of sampling strategy. The frequency ( $f$ ) indicates the frequency of mentions, whereas $(n)$ indicates the number of studies where this is more relevant.

\subsubsection{Research methods}

Among the 265 studies, qualitative and mixed-methods studies accounted for the majority, each making up 42\% $(n=110)$ and $40 \%(n=106)$ respectively, and the remaining $18 \%$ of studies $(n=49)$ are quantitative (Figure 5 ).

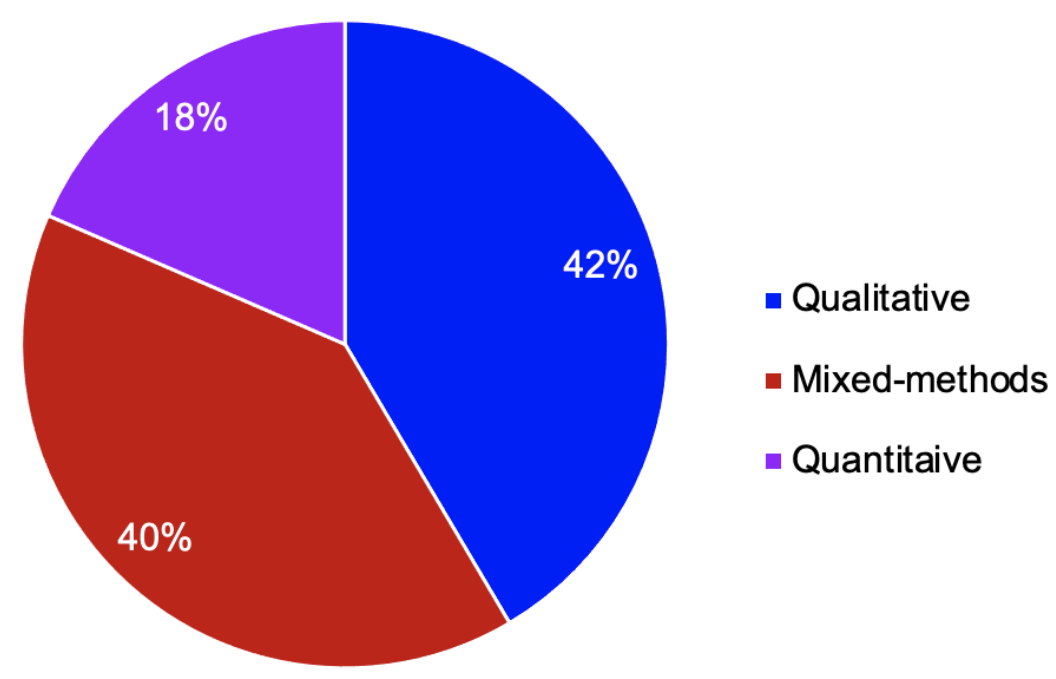

Figure 5. Distribution of studies by research methods

Due to the conceptual complexity and various views surrounding mixed-methods research, in this review we consider a study as mixed-methods when both qualitative and quantitative data were present. However, we would like to highlight that many studies claimed to be mixed-methods without making use of both qualitative and quantitative 
data in a meaningful and rigorous manner. Furthermore, 37\% $(n=39)$ of all the mixed-methods studies did not report their methods of qualitative analysis, while 18\% $(n=19)$ of them did not specify their methods of quantitative analysis. Such discrepancies perhaps reflect bias in journal review processes such that reviewers may pay more attention to quantitative analyses while overlooking the rigour of qualitative analyses. The lack of scrutiny and critical engagement with qualitative analyses could potentially compromise the trustworthiness of the research on TPD.

\subsubsection{Research designs}

As shown in Figure 6, the majority of research designs were cross-sectional (57\%) followed by experimental (25\%) and longitudinal studies (18\%). The small proportion of longitudinal designs echoed the lack of sustainability surrounding TPD or evidence for its long-term impact.

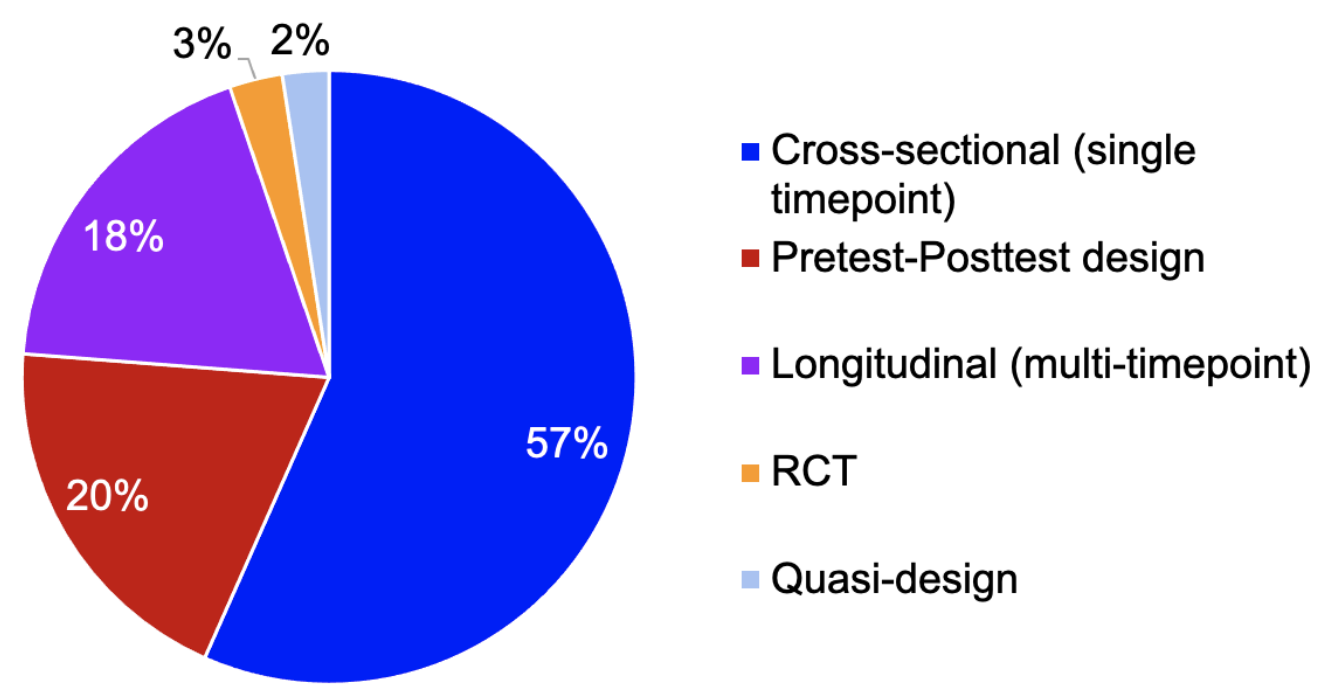

Figure 6. Distribution of study designs

\subsubsection{Methodologies and TPD designers}

As shown in Figure 7, we found a lack of diversity in methodology in the included studies. The most frequently mentioned methodologies were self-reporting (42\%) and case studies (36\%) followed by a strikingly low proportion of experiments (11\%). Participatory methodologies such as design-based research (DBR) (2\%) or action research (2\%) were rarely used. 


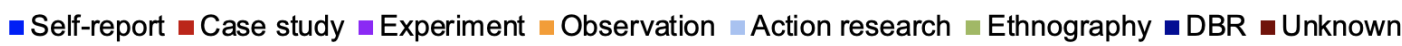

Figure 7. Methodology of included studies

Similarly, we found that an overwhelming majority of TPD designers involved academic researchers (78\%). On the other hand, participation of NGO research groups (7\%), local partners (7\%) (including local community, organisations, and teachers) as well as governments (6\%) was low (Figure 8). School-initiated TPD (2\%) programmes are also rare. This low participation of practitioners might be partially attributed to the fact that $84 \%$ of the included studies were from academic journals (Figure 4). It is thus possible that some TPD programmes initiated and led by NGOs, local partners, and schools were not published. Nonetheless, the lack of participatory methodologies and involvement of local practitioners reflect the researcher-centred approaches in the landscape of TPD research. Such approaches are likely to hinder teachers and schools from taking ownership of the TPD, and hence its sustainability. On the other hand, participatory methodologies foster collaboration between researchers and practitioners and allow TPD programmes to evolve organically in their natural environment. Such approaches help to enhance the adaptability and sustainability of the TPD as well as the ecological validity of the research.

Figure 8. Distribution of TPD designers 


\subsubsection{Data sources and methods of analysis}

As shown in Figure 9, self-reporting (52\%) was the main source of qualitative data (including in-person interviews, focus groups and open-ended surveys). Similarly, as Figure 10 illustrates, self-reporting (i.e., questionnaires using multiple-choice questions and rating scales) was the most common source of quantitative data, making up 65\% of mentions of quantitative data.

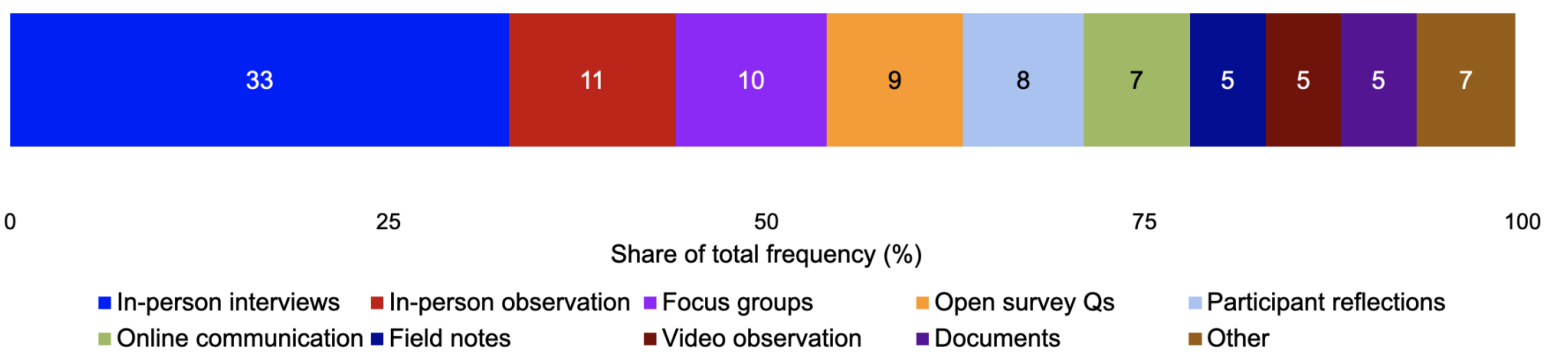

Figure 9. Distribution of qualitative data sources

38
27

50

Share of total frequency $(\%)$

19

10

32

0

25

-Multiple choice $\square$ Rating scales $\square$ Test data $\square$ Observation scores $\square$ Logfiles $\square$ Other

75

100

Figure 10. Distribution of quantitative data sources

Thematic analysis (26\%) and content analysis (25\%) coupled with systematic coding (33\%) were the most commonly used methods of qualitative analysis (Figure 11).

Simple statistical techniques, such as descriptive statistics (48\%) and simple parametric tests (18\%) were the most commonly mentioned methods of quantitative analysis (Figure 12). 
Figure 11. Distribution of qualitative analysis methods

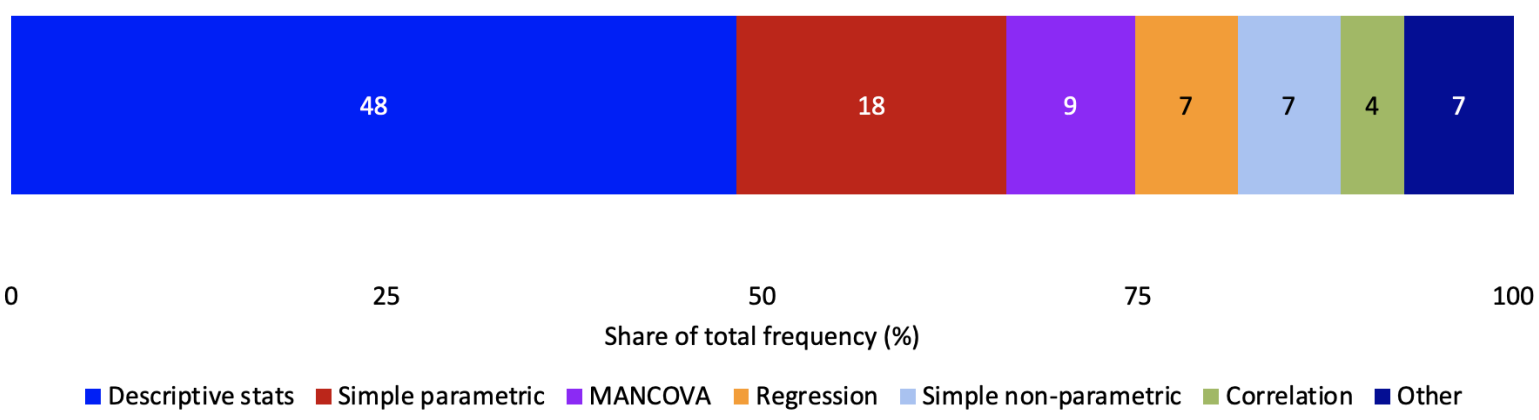

Figure 12. Distribution of quantitative analysis methods

\subsubsection{Sample}

\section{Sampling strategy}

Overall, more than a quarter of the studies $(27 \%, n=78)$ did not specify their sampling strategy. More specifically, $30 \%$ of the qualitative studies, $31 \%$ of the quantitative studies and $28 \%$ of mixed-method studies did not report on their sampling strategies. It is difficult to judge the validity and limitations of these studies without knowing the sampling strategies.

Figure 13 shows that among the sampling strategies used (which could be more than one strategy per study), purposive and volunteer had the highest frequencies (34\% and $27 \%$ respectively) followed by random sampling (21\%) and convenience sampling (16\%). 


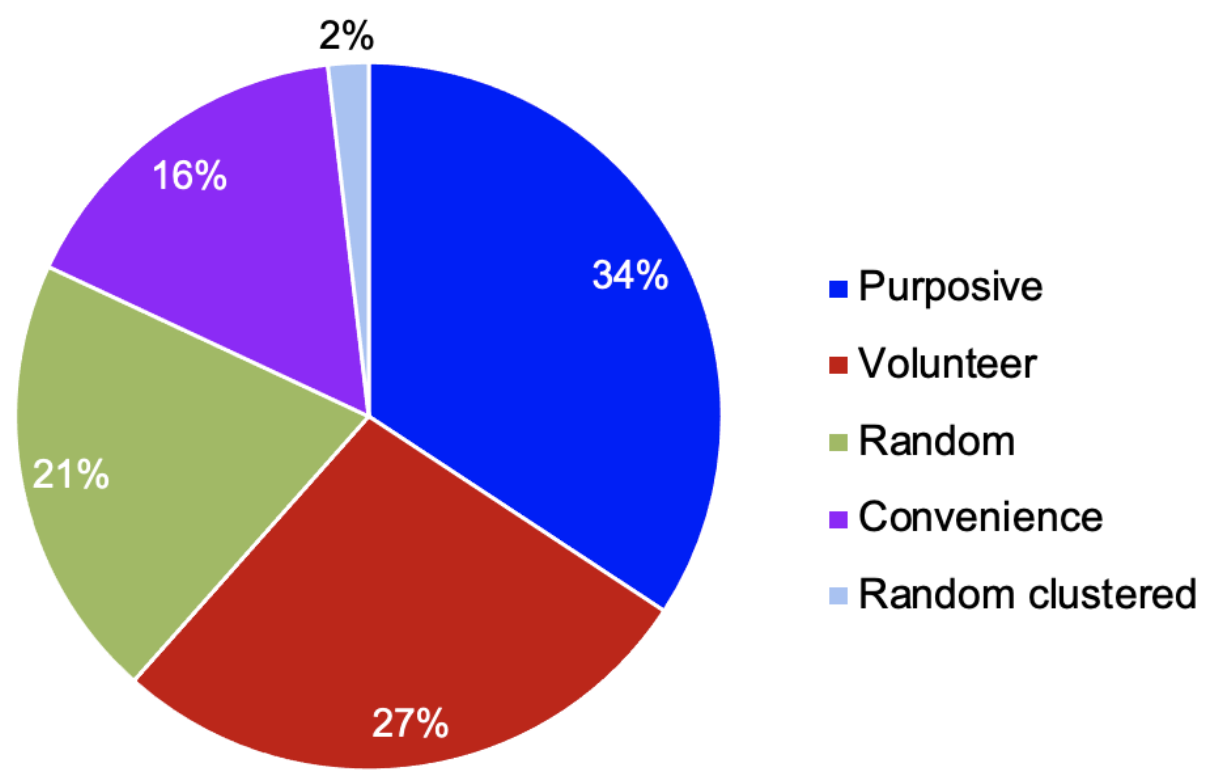

Figure 13. Sampling strategies

\section{Sample size}

The sample size was unreported in $8 \%(n=22)$ of the studies. As shown in Figure 14, the range of sample sizes varied enormously, from 1 to 44145 $(M=421, M d n=35, S D=3046)$. Approximately half of the studies (51\%) had a sample size of fewer than 50 participants. 


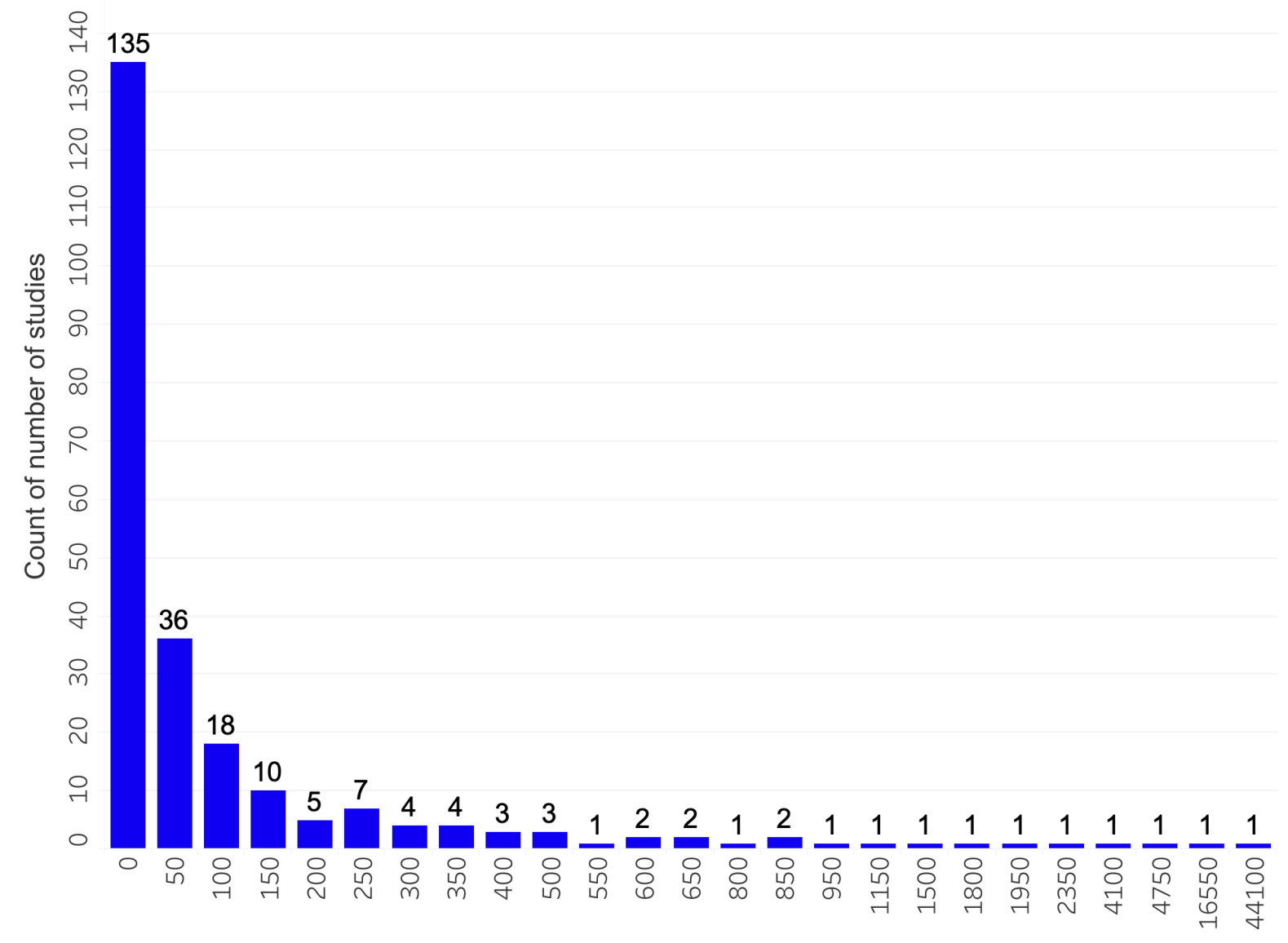

Sample size

Figure 14. Histogram showing whole sample sizes

\section{Teacher age and experience}

Data on teacher age and experience were largely unreported across the dataset. Only $8 \%(n=21)$ of the studies reported on mean teacher age; mean age across the 21 studies was 32 years old. Additionally, only $6 \%$ of studies $(n=14)$ reported on average years of teacher experience; the mean across these studies was 11 years. 


\section{Results from thematic coding: characteristics of the TPD studies}

The findings in this section describe the study settings, audiences, types of technology, TPD foci, and types of outcomes. These results derive largely from the thematic coding exercise described in 3.2.2; highlights from the results are presented, while frequencies ( $f$ ) for each individual code are shown in Appendix C. Frequencies will, in most cases, exceed the number of studies found for this systematic review since a single study may contain more than one code for the specific variable that is being presented.

\subsection{Studies by research question}

Of the 265 studies identified for this systematic review, RQ1 ('tech for TPD') appeared as the focus of inquiry in the highest number of studies ( $n=170)$. This was followed by RQ2 ('TPD for tech for teaching': $n=777$ ) and RQ3 ('TPD for tech for student learning': $n=57)$. This included both studies which researched these questions in isolation or with one of the other research questions (Figure 15).

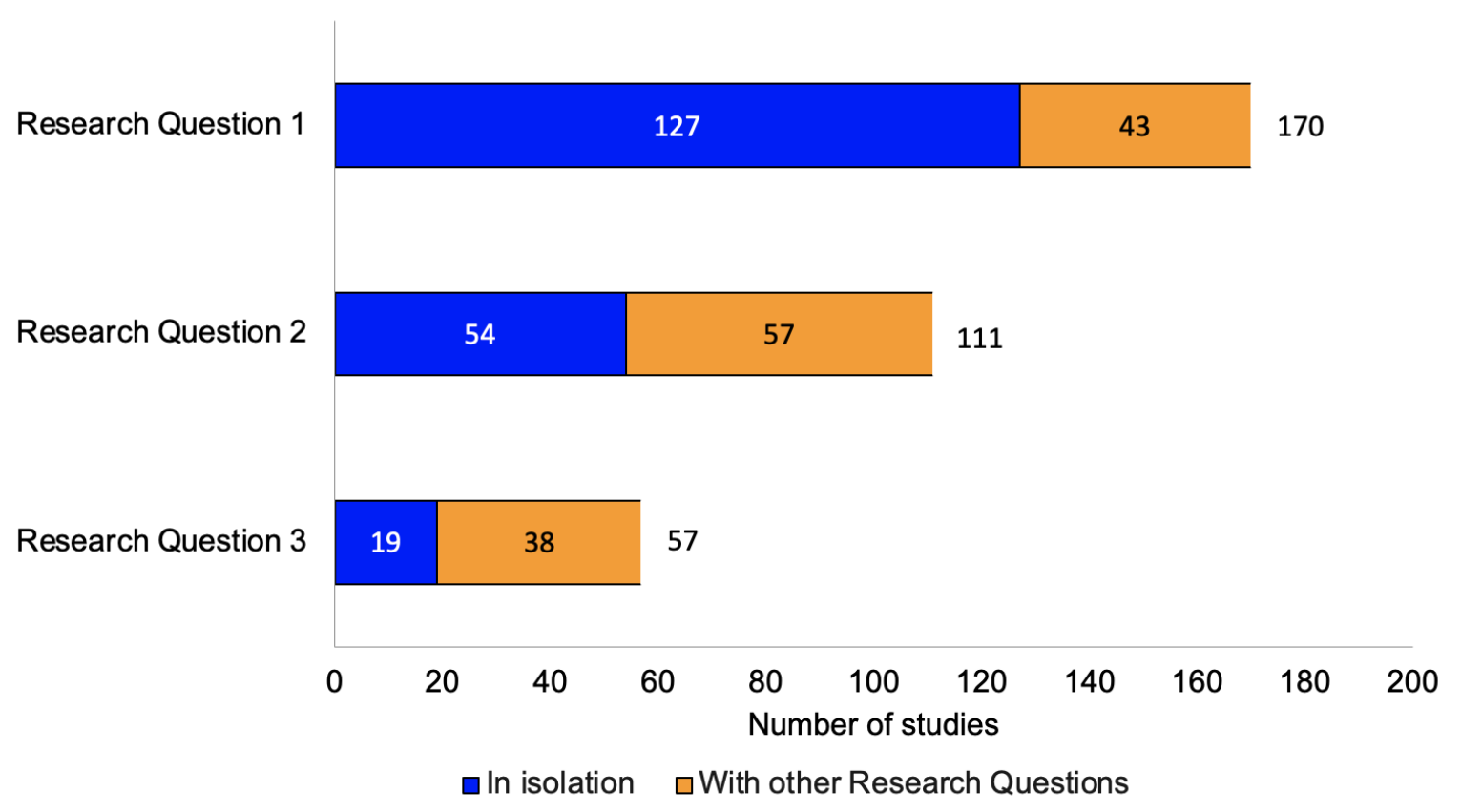

Figure 15. Distribution of studies by research question

\subsection{Regional distribution}

The systematic review identified that of the 136 LMICs, only 50 (37\%) had a study that focused on any of the three research questions. Figure 16 breaks 
this down by region according to each of the research questions. It should be noted that from a global perspective, while the SSA region had the highest share of LMICs with studies (37\%), $60 \%$ of countries in SSA had no study. ${ }^{2}$ Overall, for the 50 LMICs with studies focusing on any of the three research questions, the majority of countries (31) had between one and four studies; and there were 86 countries that were not represented in any of the studies reviewed (See Appendix E for a detailed breakdown of the number of studies by country and by country income-level).

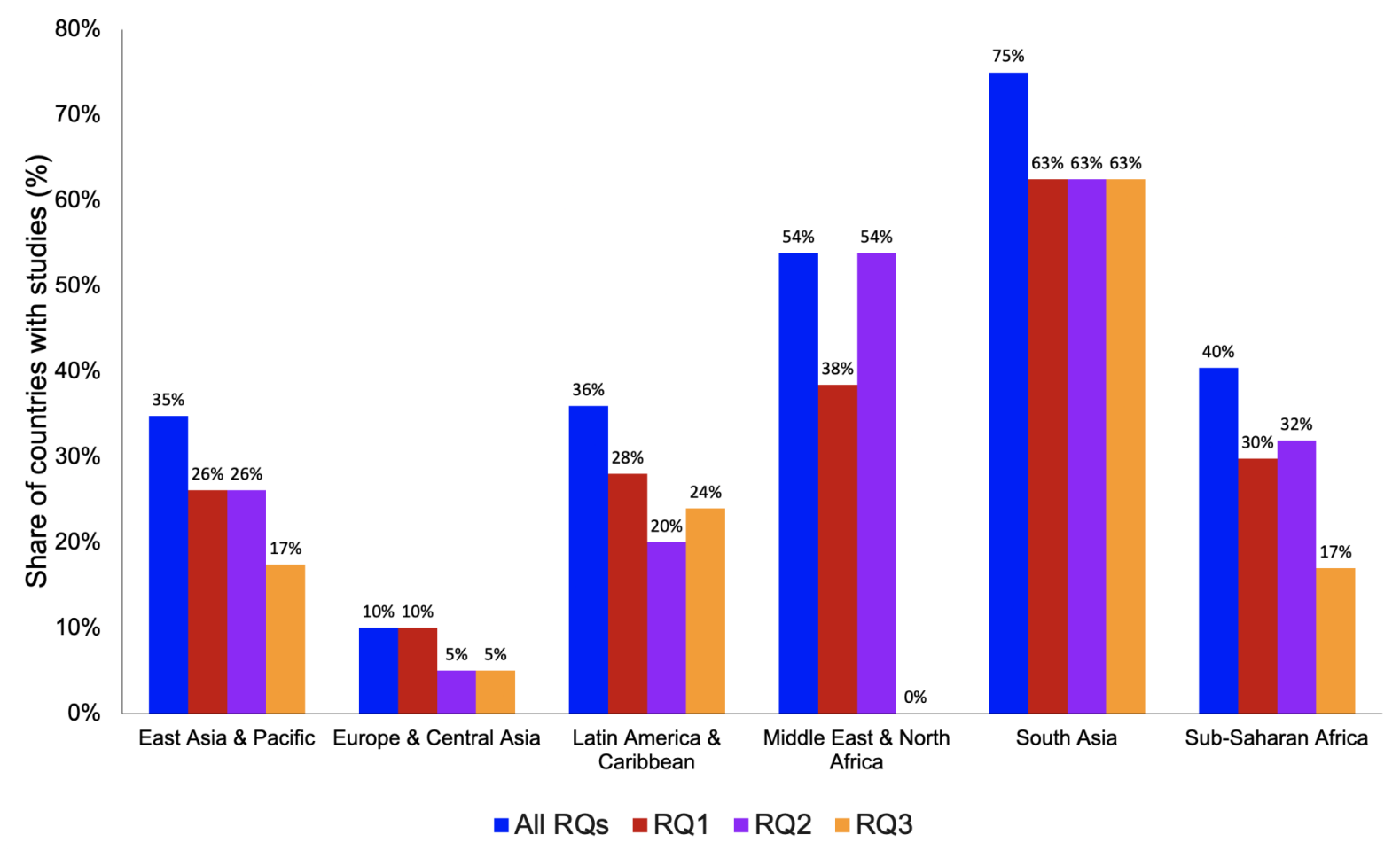

Figure 16. Share of LMICs by region with a study on $R Q 1 / R Q 2$ / $R Q 3$

\subsection{TPD settings and audiences}

In TPD, teacher learning may take place on-site (e.g., in government or private schools, or teacher training colleges) or off-site (including in district centres or through peer communication and support, for instance, via online communities of practice). It may take place informally, or via formal taught programmes and workshops; and it can be targeted towards pre-service or in-service teachers, or particularly for those teachers who do not have qualifications (e.g. contract or volunteer teachers, particularly in humanitarian or emergency settings). Teachers of all grade levels and subjects can participate in the TPD. The next three sections provide data

\footnotetext{
${ }^{2}$ This is due to the SSA region having the highest number of LMICs. It accounts for over one-third of all LMICs globally.
} 
on the TPD settings and TPD audiences that were most common in the studies reviewed.

\subsubsection{TPD settings}

Government schools (38\%, $f=116)$ and teacher colleges $(33 \%, f=101)$ emerged as the dominant research settings (Figure 17). At the other extreme, there was a dearth of research focusing on community schools $(2 \%, f=6)$ or informal contexts $(1 \%, f=4)$. From an equity perspective, it is important to note that student populations in such contexts are more likely to come from marginalised groups.

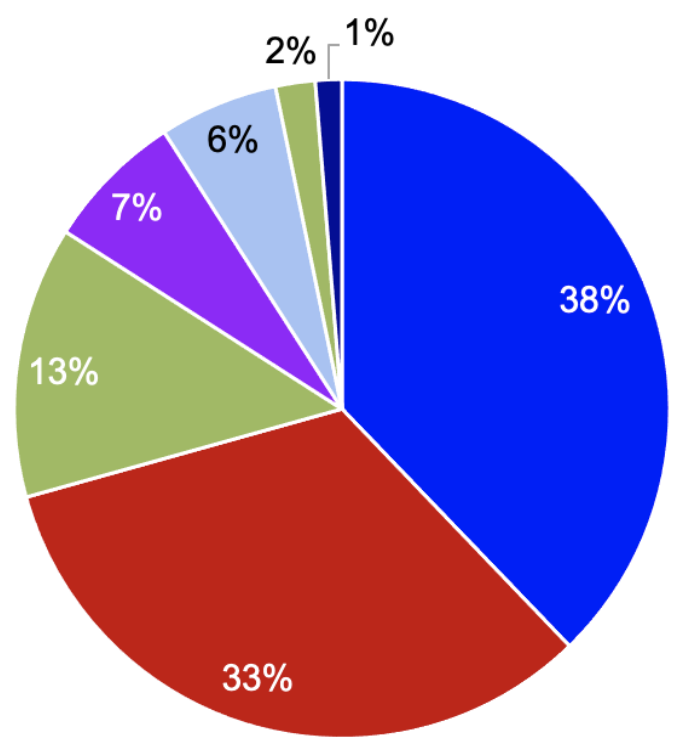

- Government school (K-12)

- Teacher college

- Remote/rural area

- Other context

- Private school

॥ Community school

- Informal education

Figure 17. TPD setting

\subsubsection{TPD audience}

In-service teachers formed the main focus of studies (58\%, $f=176)$. This was significantly larger than studies with pre-service teachers (32\%, $f=96)$, as evident in Figure 18. Comparatively few studies focused on unqualified in-service teachers $(2 \%, f=6)$ or teacher educators $(5 \%, f=77)$. At the primary level, $25 \%$ of in-service teachers in 2019 were estimated to be unqualified in LICS and 16\% for MICS ( 1 UNESCO Institute for Statistics (UIS), 2019). There is thus a need for more studies looking at the role of technology specifically relating to unqualified teachers. 


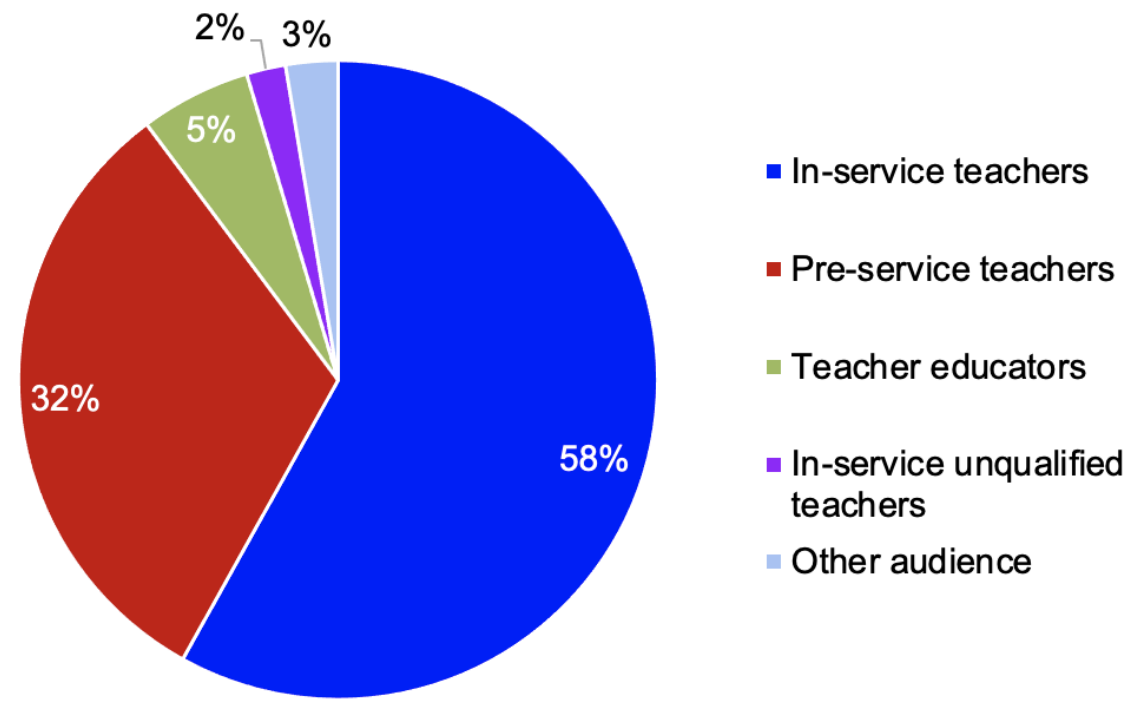

Figure 18. TPD audience

\subsubsection{Subject and education level}

Figure 19 indicates that mathematics $(26 \%, f=77)$, science $(23 \%, f=67)$ and second language learning / English as an additional language (SLL / EAL) $(21 \%, f=61)$ were the subjects most frequently mentioned. These three subject areas made up over two-thirds of all frequencies relating to the subject area. Literacy, on the other hand, was much less frequently mentioned $(13 \%, f=13)$. This is despite pre-Covid-19 statistics estimating that the majority of 10 -year-old children in LMICs could not read a simple text (see Introduction).

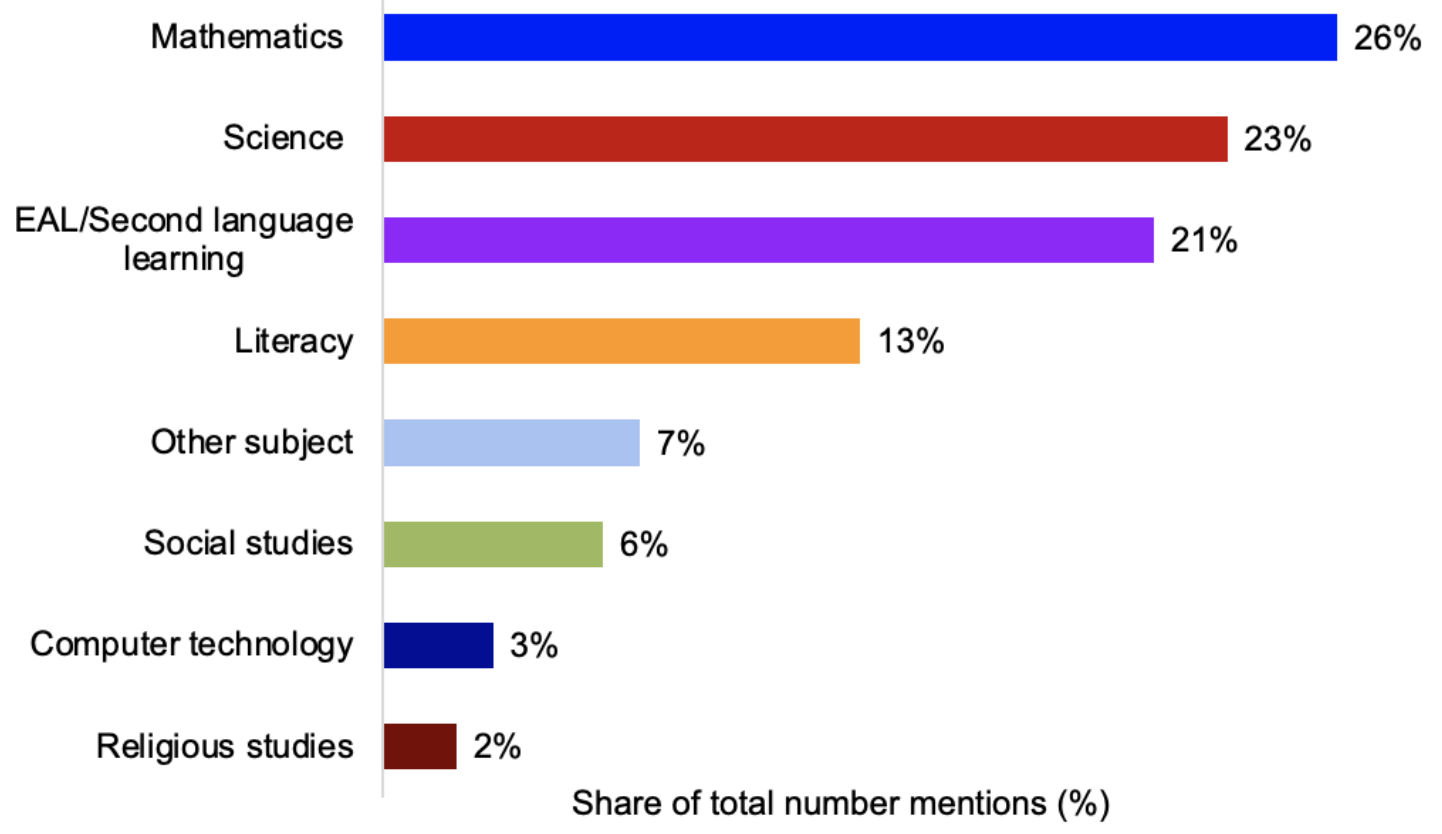


Figure 19. Frequencies of mentions in TPD subjects

This becomes less surprising when considering the interaction with education level. An emphasis on literacy is normally associated with pre-primary and primary levels of education. However, the systematic review found that secondary education was much more frequently mentioned ( $52 \%, f=140)$, compared to early childhood education $(3 \%, f=7)$ and primary education $(40 \%, f=107)$ (Figure 20$)$. Focus on vocational education $(5 \%, f=72)$ was also scarce.

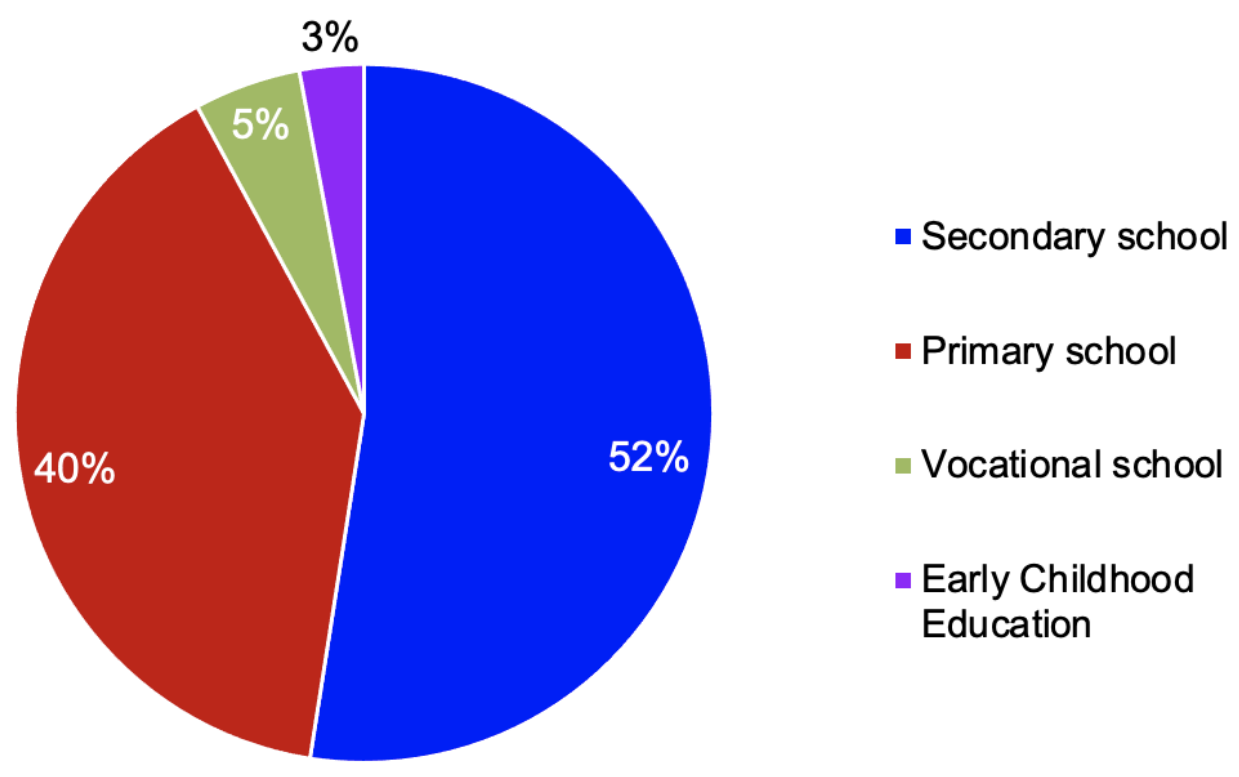

Figure 20. Distribution of mentions of educational level

When zooming in on $\mathrm{RQ1}$, by region, there was also considerable divergence regarding focus subject area (Figure 21). More research focused on literacy in SSA than in other regions. This could be due to the comparatively larger proportion of primary education studies in the region. Research in other regions is more concentrated around one particular subject. For instance, EAL / SLL was the main focus of studies in East Asia and the Pacific, Middle East and North Africa, and South Asia (Figure 22). The large concentration of TPD studies on EAL / SLL in South Asia relates to Bangladesh $(f=8)$, where much research focused on the FCDO-funded English in Action programme ( $\$$ Shohel \& Power, 2010). 


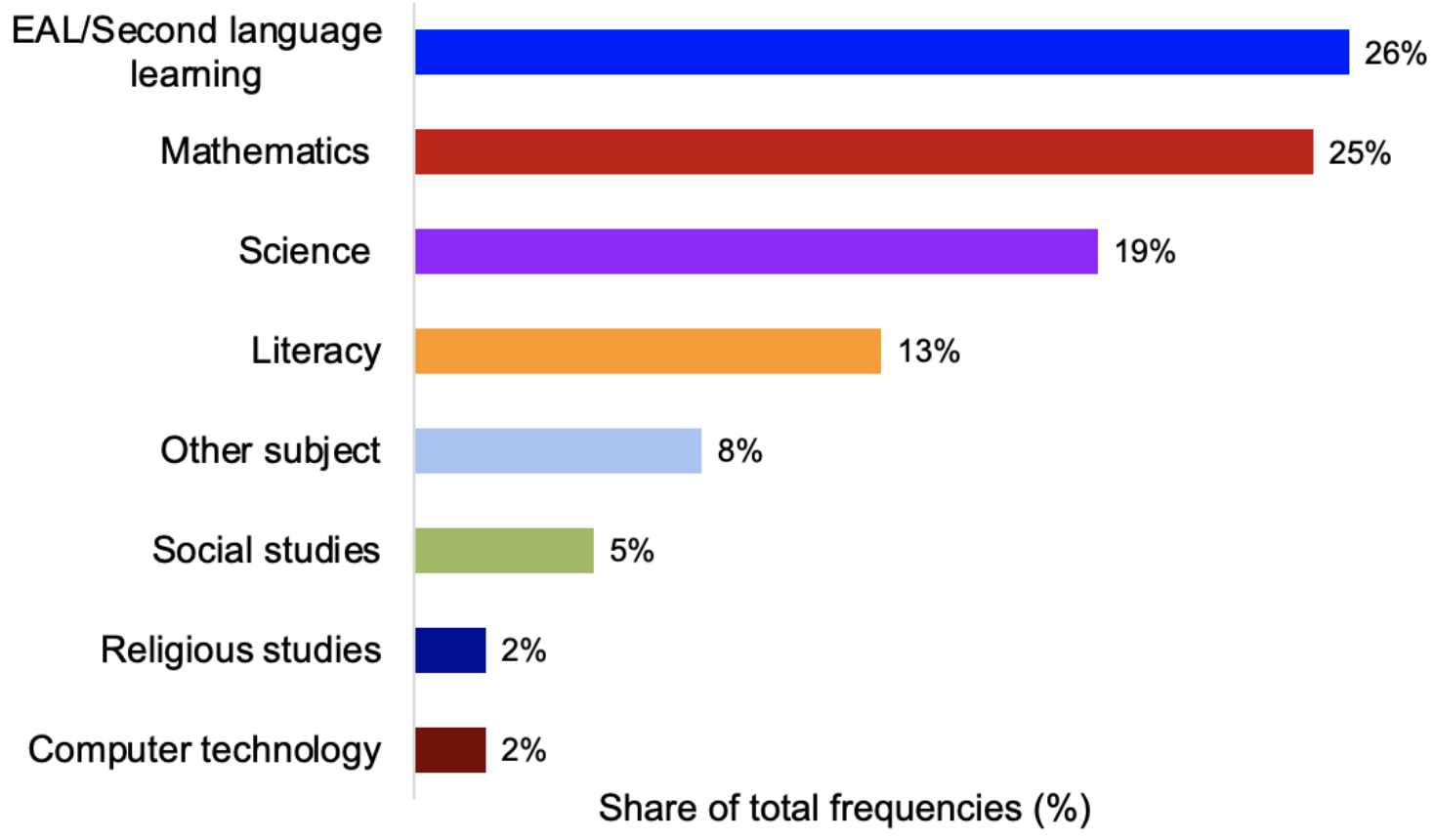

Figure 21. Subject distribution of studies in $R Q 1$

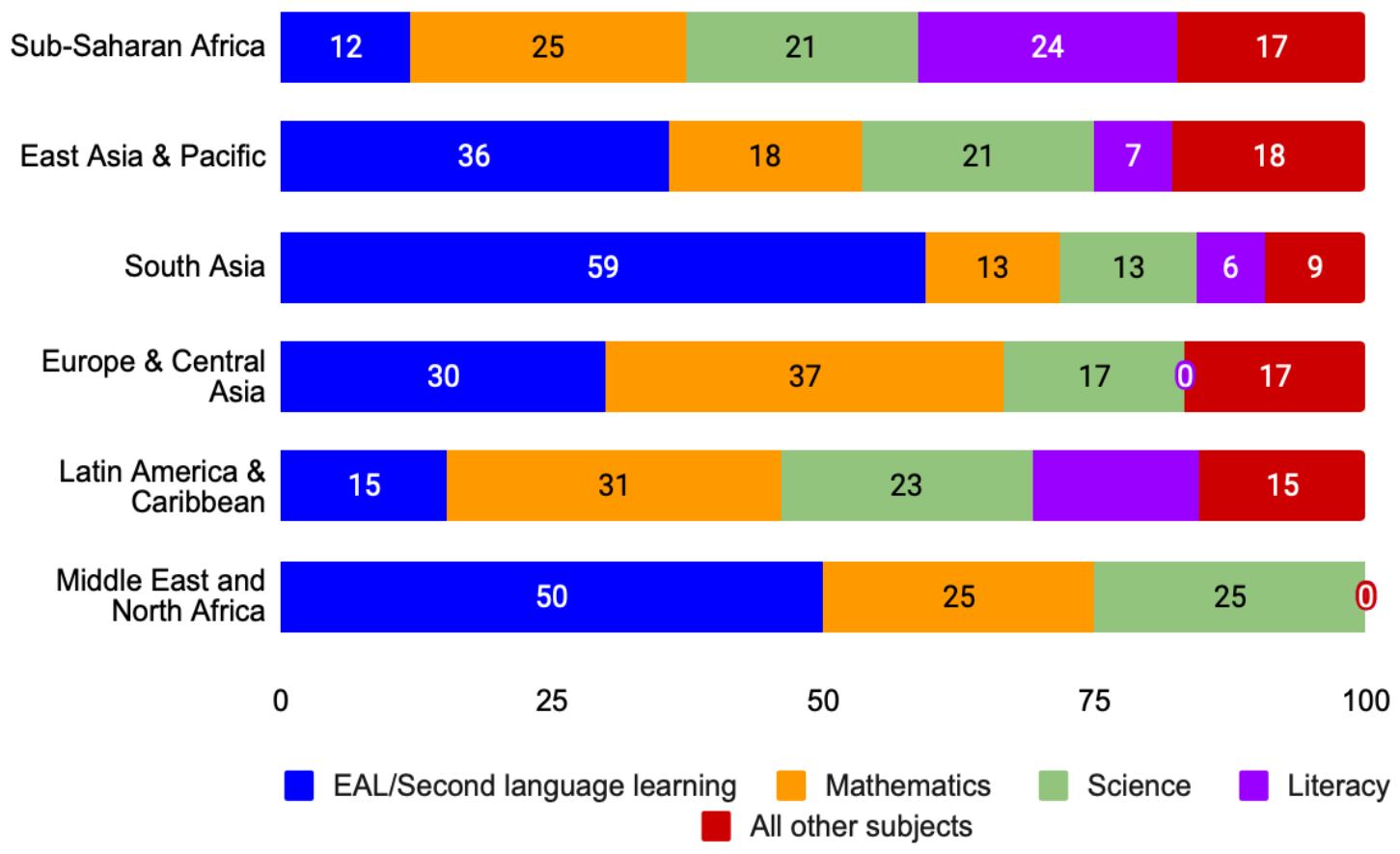

Figure 22. Subject distribution by region in $R Q 1$ 


\subsection{TPD designs and modalities}

The following section examines overarching design approaches and modes of TPD. Section 5.4.1 provides data on the TPD studies that were designed to be, for example, subject-specific, sustainable, or scalable; while Section 5.4.2 provides a snapshot of the types of modes that were used in the TPD studies (e.g. active learning, practical application, reflective enquiry, or workshop based TPD). Section 5.4.3 then presents a close-up of the types of peer support common in the studies reviewed. Collaborative teacher development supports feedback and evaluation of practices among peers, a common and critically important feature of effective pre- and in-service programmes. The following sections then build on this to examine what EdTech devices and resources were used to foster this peer collaboration and support.

\subsubsection{TPD designs}

As shown in Figure 23, subject-specific TPD was the most common type of design in LMICs, making up nearly half of the designs mentioned. It is surprising that sustainability and scalability, respectively making up 19\% and $13 \%$ of the total mentions, were not more often considered when designing TPD programmes in LMICs. Systems thinking approaches, such as the ecological framework, had the lowest frequency (7\%). Other designs (15\%) include approaches whose total mentions did not exceed or equal three (e.g. TPD designed for refugee teachers or TPD designed for teachers with disabilities); as a result, they were not included in the coding scheme as separate codes. 
Subject-specific approach

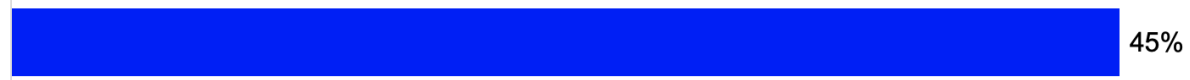

Sustainability

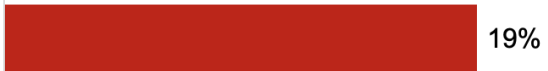

Scalability

$13 \%$

Ecological framework $7 \%$

Other design $15 \%$

Share of total frequencies (\%)

Figure 23. Types of TPD design

\subsubsection{TPD modes}

In general, we found that modes of TPD shifted away from passive learning to more active learning. As shown in Figure 24, practical application (e.g., having teachers apply what they learned in the classroom) and active learning (e.g., having teachers actively participate in the learning process through hands-on activities) were the most commonly mentioned TPD modes, each making up $17 \%$ and $15 \%$ of the total mentions of TPD modes. Workshops (15\%) and reflective practice / inquiry (12\%) were also popular modes of TPD. In these cases, teachers had some agency in directing their learning while benefiting from external support (e.g., reading materials, expertise of TPD facilitators). TPD modes that involve passive learning with little teacher agency, such as printed guides, were used less often (5\%). Other modes and methods (21\%) include self-directed learning, lectures, modelling, cascade model, and teacher-oriented approach. 


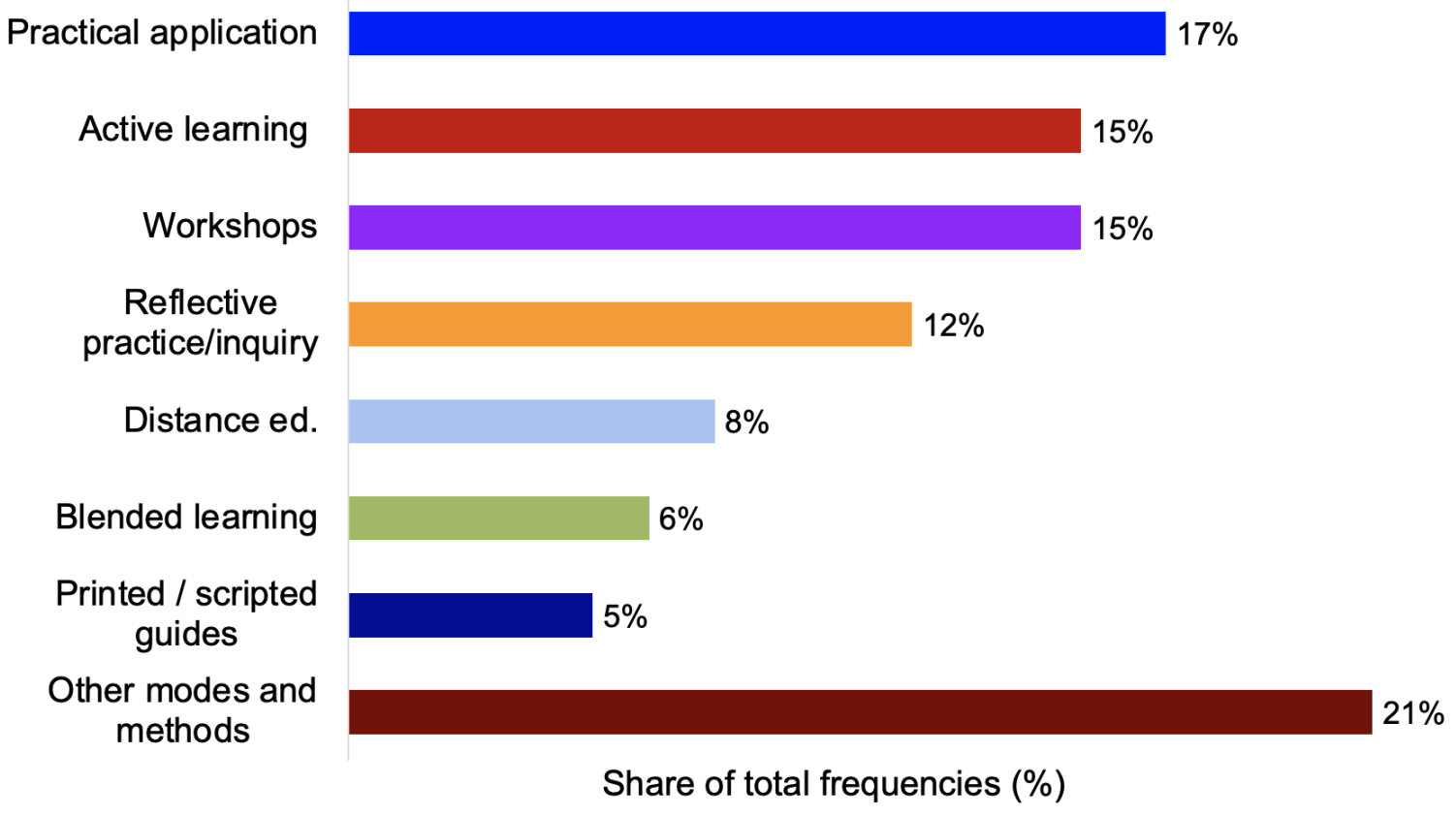

Figure 24. TPD modes

\subsubsection{Forms of peer support}

As seen in Figure 25, support from senior experts (i.e. researchers, leading teachers, TPD facilitators) and from junior colleagues (i.e. teacher peers) were the most common forms of peer support in TPD, making up 25\% and $23 \%$ of the mentions respectively. These two forms of peer support are rather flexible, not necessarily having a defined structure. For example, asking peer teachers for advice on lesson plans and teaching resources could be a form of junior peer support. Benefits of peer support (22\%) were often recognised and mentioned in the included studies. Less common forms of peer support included remote peer feedback / evaluation (12\%) and communities of practice (11\%), which require more structure and organisation.

Mentoring (4\%) and coaching (3\%) were the least common forms of peer support perhaps due to the fact that they are usually time- and resource-intensive. Given the important role of — and need for — highly skilled peers, teacher trainers, and educators, the limited number of studies examining mentors and coaches presents an evidence gap. More research is needed to examine how educational technologies can be used to support mentors and coaches and better equip them with the skills, knowledge, and resources needed to support pre-service and in-service teachers in LMICs. 


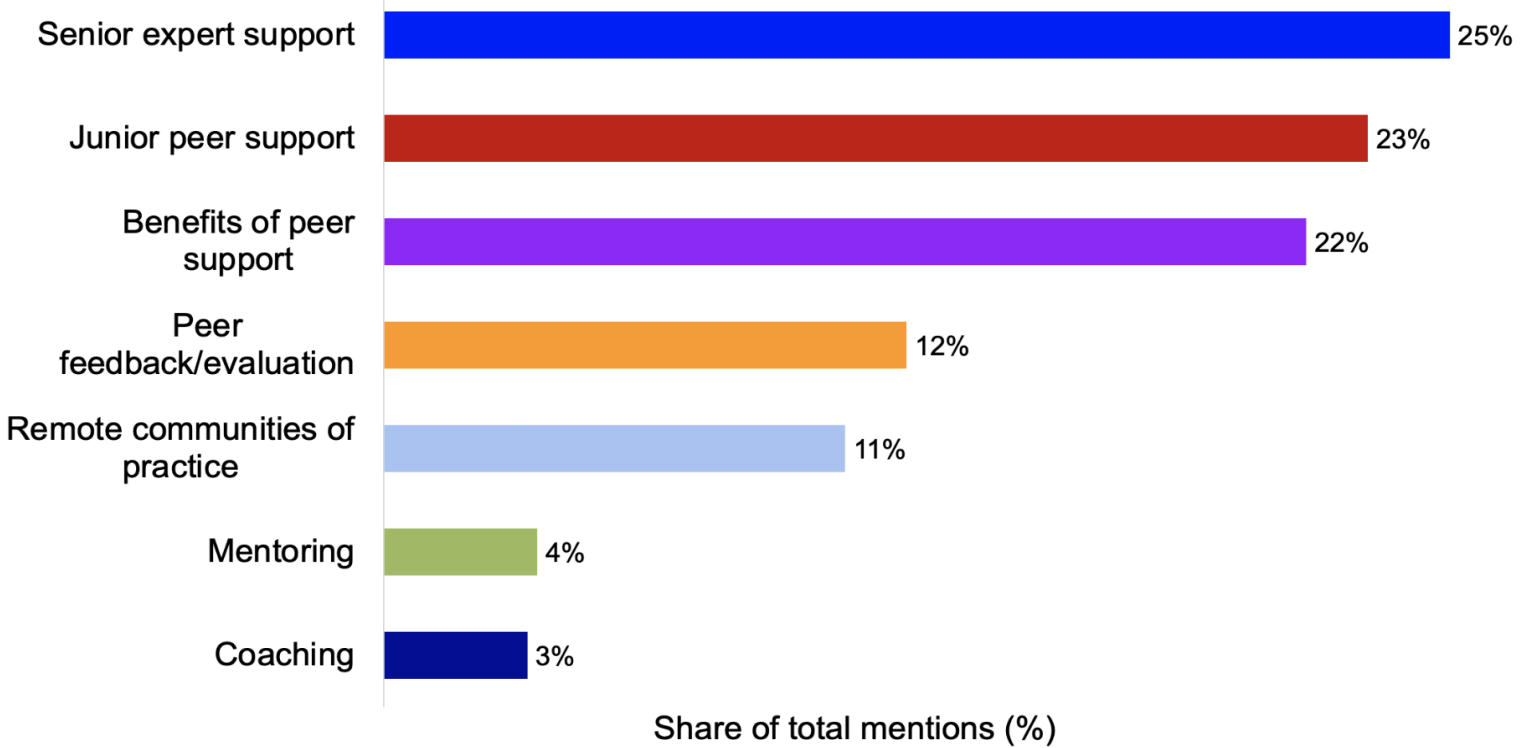

Figure 25. Forms of peer support

\subsection{Technological devices and resources}

\subsubsection{Technological devices used in studies}

Computers were the most prevalent device in the 265 studies reviewed: in $42 \%$ of cases ( $f=175$ ) where a tech device was mentioned at all, these referred to laptop or desktop computers (Figure 26) and most (54\%) of these involved no additional devices. A further $19 \%$ of cases ( $f=80$ ) referenced smart devices (e.g., smartphones or tablets). Research featuring all other types of devices included multiple forms of technology. Broadcast media (which includes devices such as radios and televisions) and phones may often be the most suitable devices in low-resource contexts, yet comparatively fewer studies focused on these. 


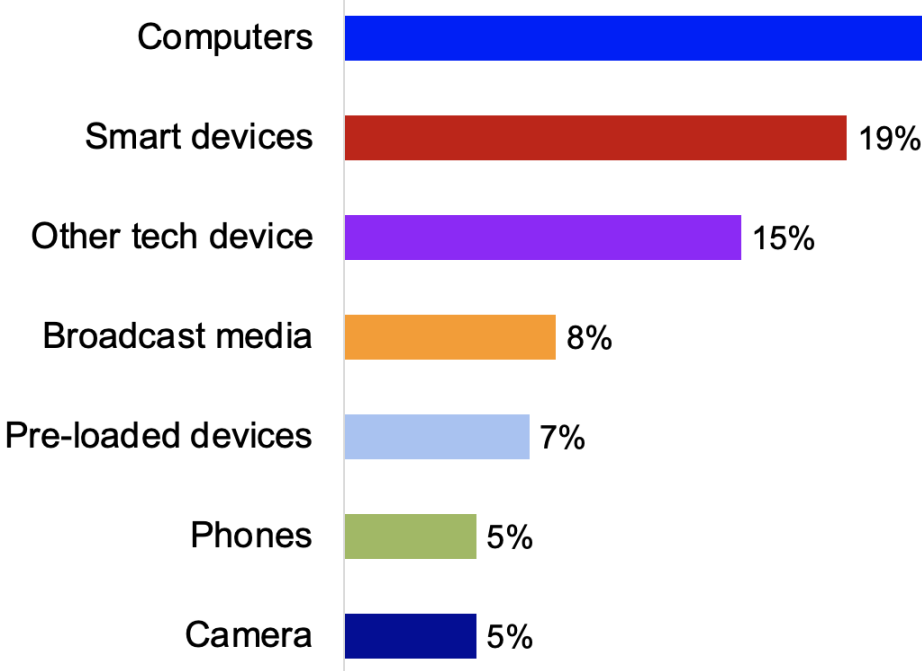

Share of total mentions (\%)

Figure 26. Frequencies of mentions of tech devices

When looking closely into the use of technology for TPD (RQ1), computers still appeared as the primary or secondary device across the literature. However, notable exceptions emerged when disaggregating by context or geographic region. In remote / rural areas and community schools, frequency of mentions of smart devices was either equal to or more than the frequency of mentions of computers (Figure 27). The same was also true in SSA and South Asia when looking at regional breakdowns (Figure 28).

\begin{tabular}{|c|c|c|c|c|c|c|c|c|c|}
\hline Teacher college & 56 & & 17 & 5 & 46 & 6 & 5 & 8 & \\
\hline $\begin{array}{r}\text { Government } \\
\text { school (K-12) }\end{array}$ & 36 & 26 & 9 & 9 & 7 & 3 & 1 & 11 & \\
\hline $\begin{array}{r}\text { Remote/rural } \\
\text { area }\end{array}$ & 27 & & 14 & 10 & 8 & 8 & 6 & 6 & Computers \\
\hline $\begin{array}{r}\text { Other context / } \\
\text { off-site }\end{array}$ & 35 & 24 & 18 & & 6 & 12 & & 6 & $\begin{array}{l}\text { Smart devices } \\
\text { Phones }\end{array}$ \\
\hline Private school & 41 & 24 & 6 & 12 & & 12 & 2 & 6 & Pre-loaded devices \\
\hline $\begin{array}{r}\text { Community } \\
\text { school }\end{array}$ & 33 & 33 & & & 33 & 3 & & 0 & $\begin{array}{l}\text { Broadcast media } \\
\text { Camera }\end{array}$ \\
\hline $\begin{array}{r}\text { Informal } \\
\text { education }\end{array}$ & & & & & & 25 & & 0 & Other tech devices \\
\hline 0 & 25 & 50 & & 75 & & & & 100 & \\
\hline
\end{tabular}

Figure 27. Tech device by TPD context in RQ1 


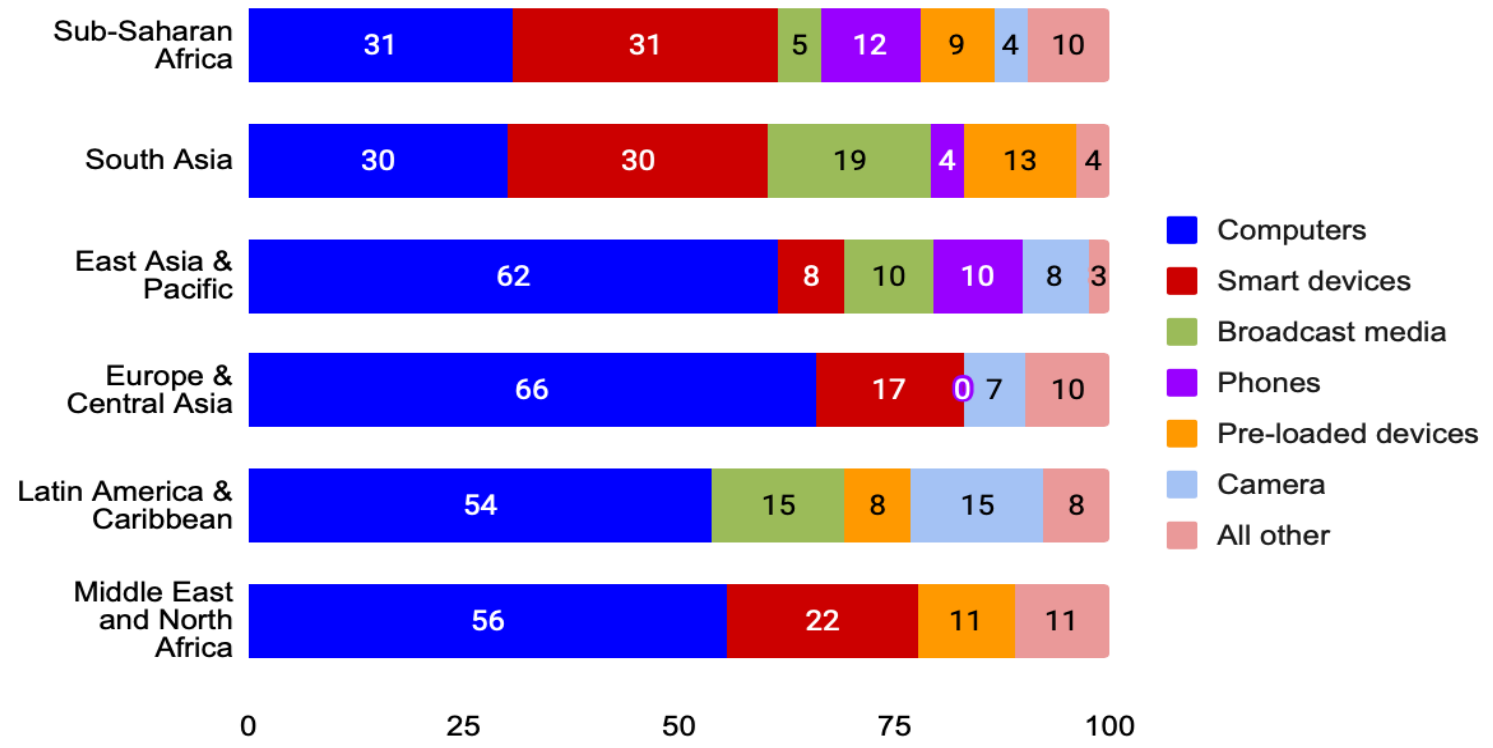

Figure 28. Tech device by TPD region in $R Q 1$

\subsubsection{Technological resources used in studies}

Studies tended to be concentrated around certain tech resources. In particular, video resources, web resources, and software application resources collectively comprised $61 \%$ of tech resources mentioned (see Figure 29). Other tech resources were frequently mentioned in studies (e.g., audio resources, Open Educational Resources [OERs], digital presentations), but this was often in conjunction with additional tech resources.

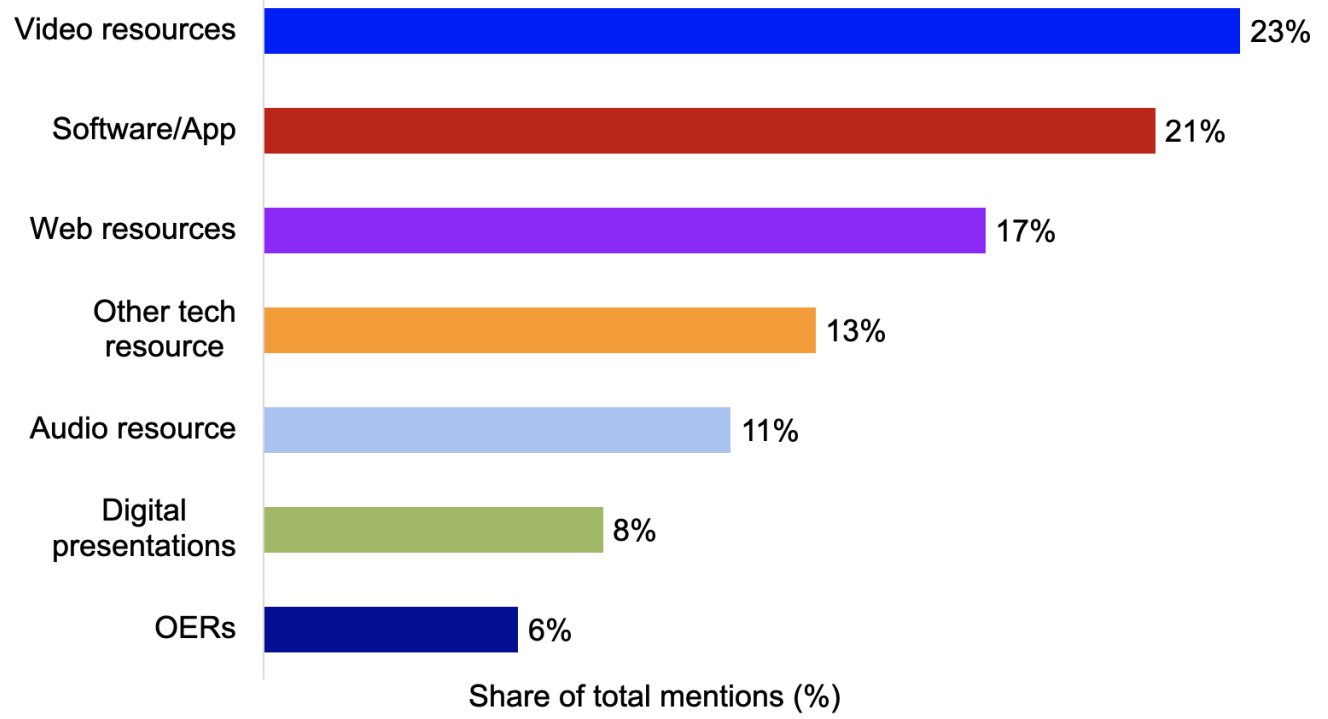

Figure 29. Tech resources 


\subsubsection{Technology for communication in TPD}

Figure 30 shows that social media (23\%) was the most popular communication technology for tech-supported TPD in LMICs - probably because it is versatile, accessible, and familiar to teachers. For instance, access to mobile devices among adults has reached 100\% in South Africa, Namibia, and Zimbabwe (^Laurillard et al., 2018). Virtual learning environments / learning management systems (VLE / LMS) (22\%) were also frequently mentioned when technology for communication in TPD is involved. Forums and emails (16\% respectively) were also commonly used.

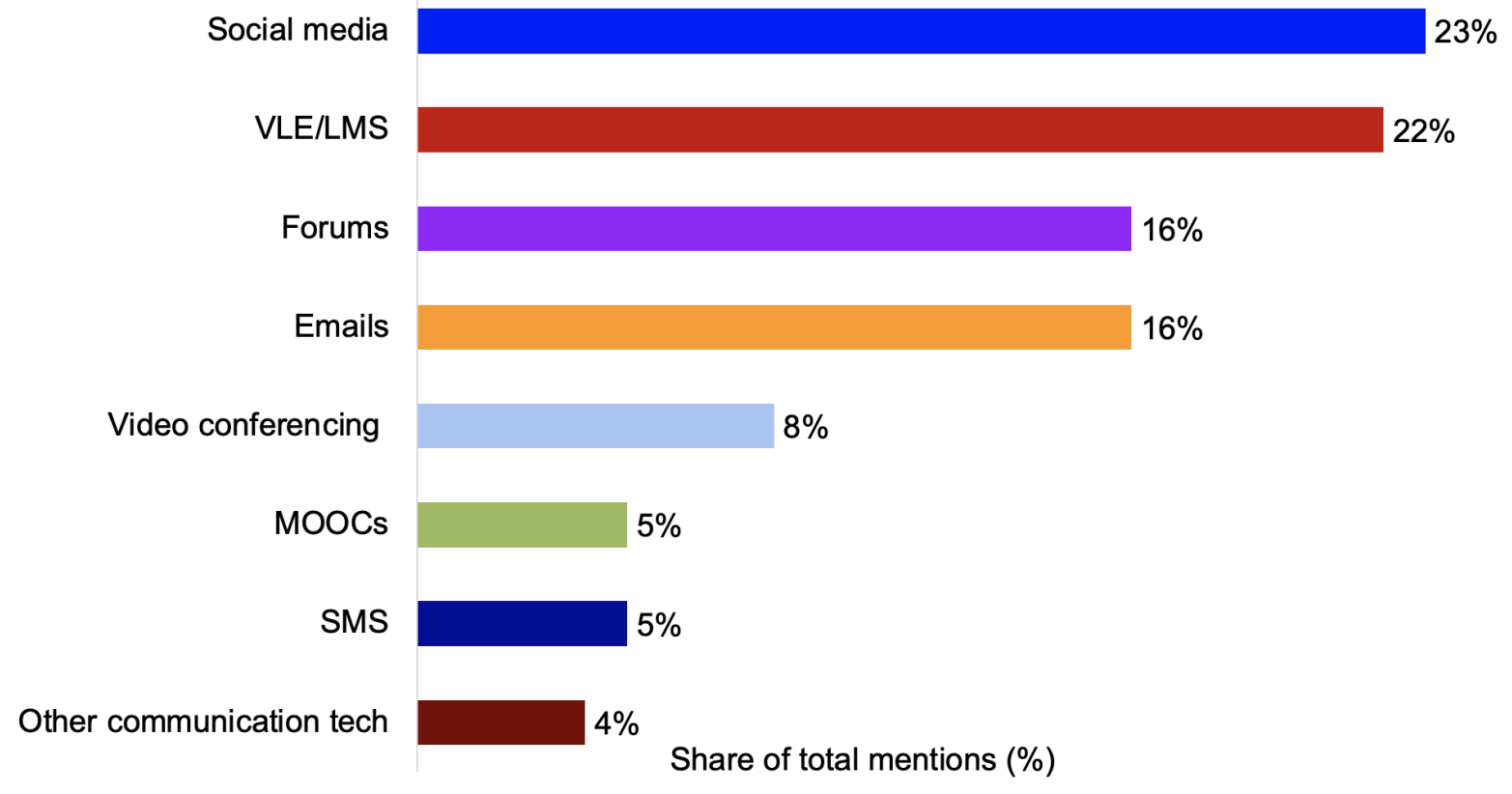

Figure 30. Technology for communication in TPD

\subsection{Identifying and measuring TPD outcomes}

\subsubsection{TPD outcomes}

While no single outcome emerged as a majority focus, teacher tech skills and awareness (13\%), teacher use of ICT (12\%), and student interest or engagement $(11 \%)$ were the most frequently mentioned outcomes in the studies collected. It seems, therefore, that the outcomes of TPD programmes are technology-driven rather than focusing on learning. The role of technology often stayed at the level of enhancing engagement and interests rather than fostering conceptual understanding and deeper learning. While student interest and engagement is an important determinant factor of learning, this finding illustrates an evidence gap. 
For this review, we were particularly interested in learning about what effects EdTech use had on changing classroom practices and ultimately, where addressed, on student learning / attainment. This focus was based on Levels 4 and 5 of $\uparrow$ Guskey's (2002) 5-point TPD evaluation framework. The majority of the studies included in this systematic review discussed multiple outcomes emanating from the use of EdTech on TPD, rather than focusing on just one. However, changes in classroom practice made up just 9\% of TPD outcomes mentioned (Figure 31). The equivalent figure for student learning outcomes was similar at $8 \%$, which is remarkable given the aforementioned statistics on low learner attainment levels in LMICs. Other outcomes of TPD (16\%) included teacher satisfaction, the creation of teaching and learning materials, teacher time management, intercultural competency, and additional outcomes that did not have a frequency larger than three (thus they were not included in the coding scheme).

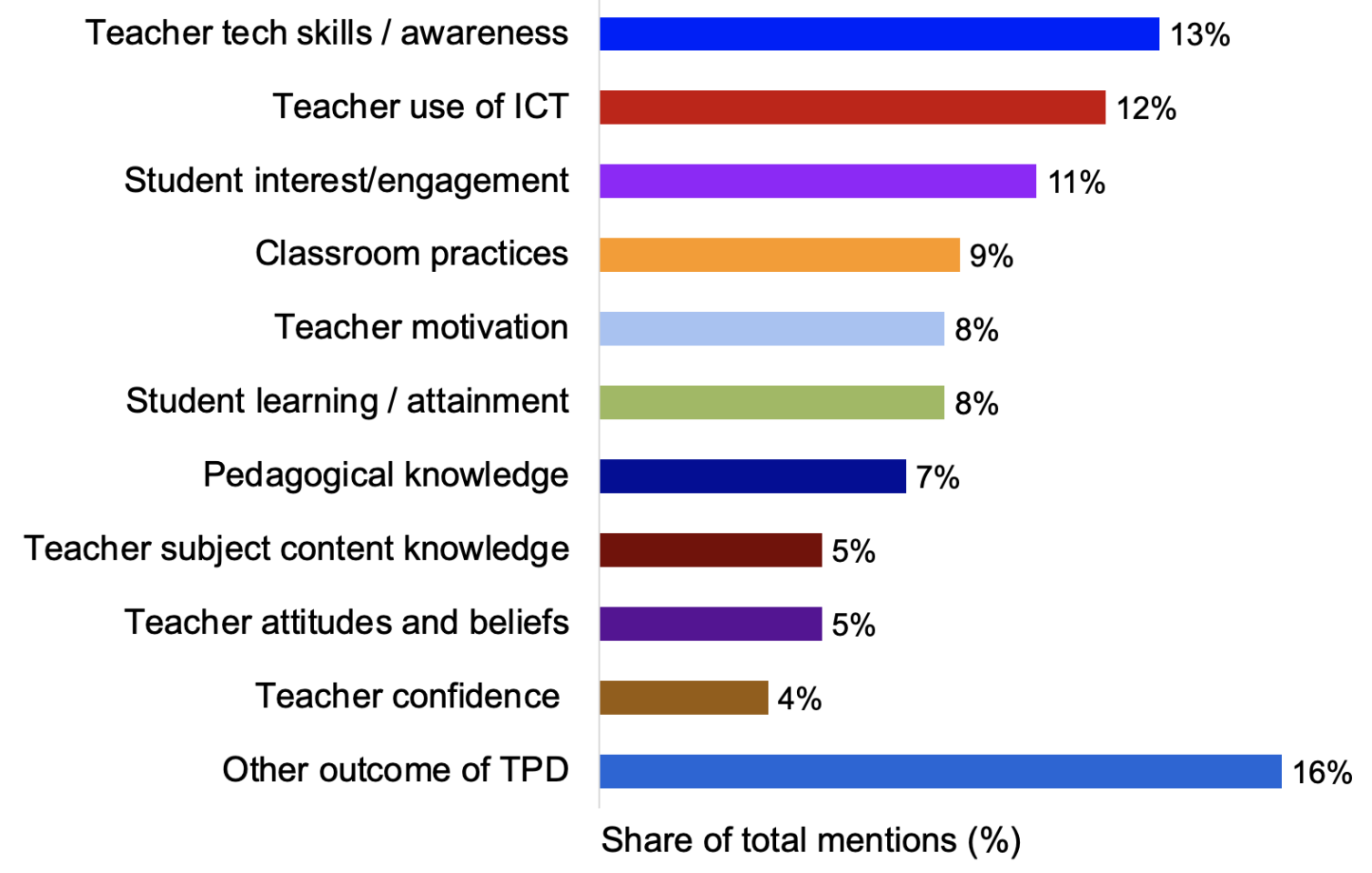

Figure 31. TPD outcomes

Zooming into RQ1 ('tech for TPD'), in all regions the proportions of studies mentioning 'changed classroom practices' and 'student learning' as outcomes remained low, despite the general consensus around the importance of these TPD outcomes. There are notable regional differences, though. The proportions ranged from $29 \%$ [rounded] in SSA to only $7 \%$ in the Middle East and North Africa. 'Changed classroom practices' featured more prominently in the studies in four regions: SSA, East Asia and the 
Pacific, Latin America and Caribbean, and South Asia. 'Student learning/attainment' was rarely mentioned in all regions apart from SSA.

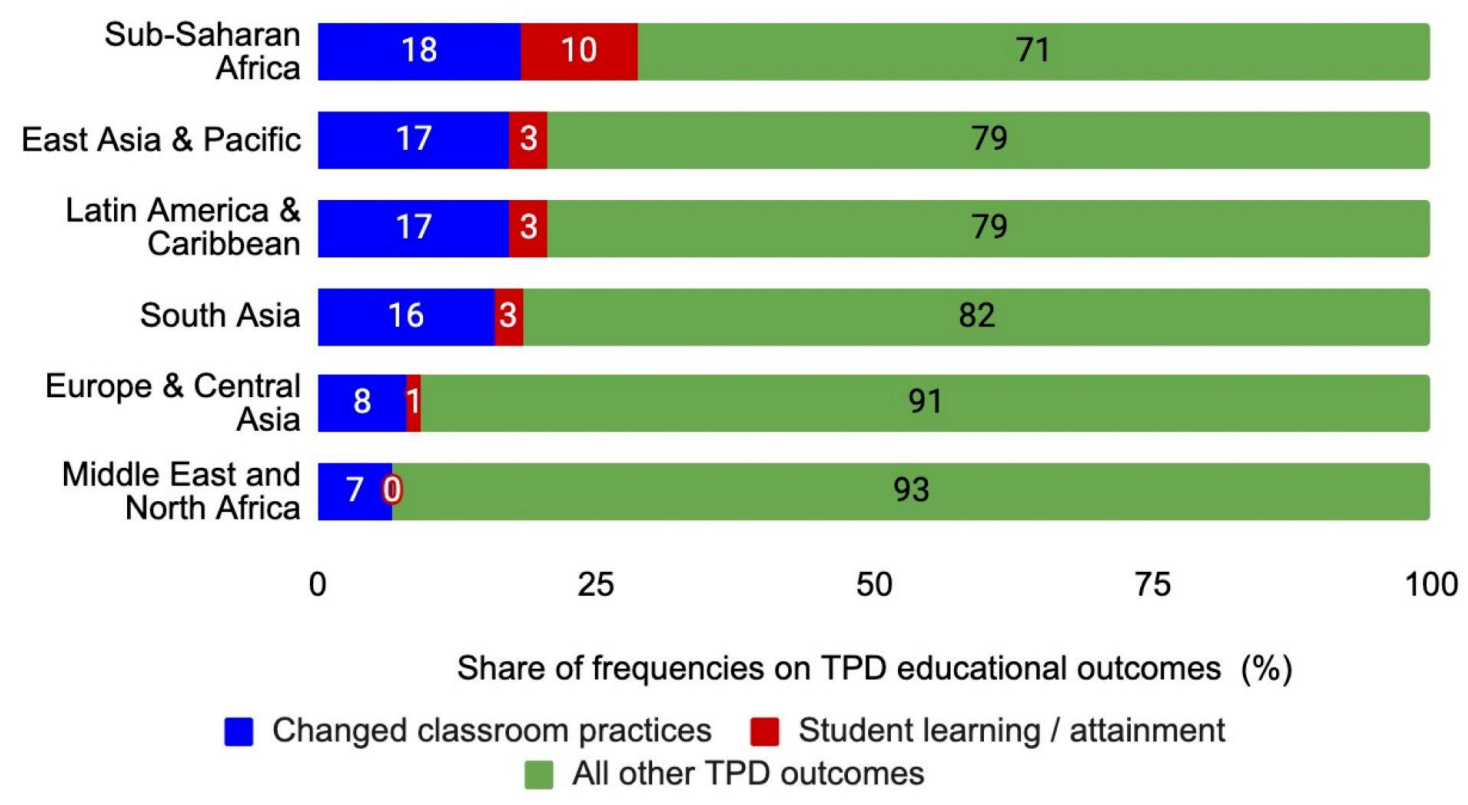

Figure 32. TPD outcomes by region (RQ1)

\subsubsection{Assessing TPD outcomes}

Most studies reviewed relied on self-reporting to measure changes in teacher knowledge and practice. For instance, of all the qualitative data collection methods used, self-reporting methods (including interview, focus group, open-ended survey, reflection) made up 60\% (see Figure 9 in Section 4). Similarly, of all the quantitative methods used, self-reporting methods (including questionnaires in formats of multiple-choice questions and rating scales) made up 65\% (see Figure 10 in Section 4). Note that data collection methods are not mutually exclusive; for example, one study could use a questionnaire assessing technological pedagogical content knowledge (TPACK) as well as classroom observations.

Assessing changes in pedagogical practices is more complex than measuring changes in teacher knowledge via questionnaires or tests (for example, the TPACK framework is a popular tool that is considered viable for measuring teachers' technological pedagogical content knowledge across time points: ^Durusoy \& Karamete, 2018; ^Qasem \& Viswanathappa, 2016). This would have contributed to why 'changes in classroom practice' were only $9 \%$ of TPD outcomes mentioned. However, through this measurement, it is unclear whether shifts in teachers' day-to-day practices occur and persist over a long period. In addition, self reports have 
well-known limitations in terms of validity - for example, questionnaires used in ^Gloria \& Oluwadara's (2016) study demonstrated teachers' improved feelings of self-efficacy towards using mobile phones as pedagogical tools, but without linking to actual changes in classroom practices.

On the other hand, non-self-reporting methods accounted for $40 \%$ of qualitative data collected; in-person observations and online communication (e.g., blog posts and social media comments) were the most common types. Among the 87 studies that had 'change in classroom practice' as a TPD outcome, only 32 (37\%) of them used observations (either in person or by video) for data collection as a source of qualitative data.

Non-self-reporting methods accounted for $32 \%$ of quantitative data collection methods, which included test data (19\%), observation scores (10\%), and log files (3\%). While test data could be a good form of assessing teachers' subject content knowledge, among the 56 studies that had subject knowledge as a TPD outcome, only 16 (29\%) of the studies used tested data to assess teacher learning.

\subsection{Factors shaping the effectiveness of TPD}

The very nature of TPD is context specific. A substantial body of literature examines the effectiveness of TPD initiatives in LMICs and highlights the economic, social, and political factors that shape the effectiveness of TPD programmes (e.g., ^Twining et al., 2013; ^ ^avrus \& Bartlett, 2012).

Infrastructure, the political environment, access to tech support and training, and the costs of physical and human TPD resources are among the contextual factors shaping TPD at the system level. At the local or individual level, teacher and student identities, school leadership, and community buy-in or support from parents also play an important role. The next two sections examine those system-level and local-level contextual factors that most commonly appeared in the studies reviewed.

\subsubsection{Contextual factors at system level}

ICT infrastructure (21\%), access to technology (20\%), access to tech support and training (19\%), and policy (15\%) were the most frequently mentioned system-level factors in tech-supported TPD in LMICs (see Figure 33).

Therefore, providing basic ICT infrastructure, access to technology, and technical support and training at a system-level is crucial for technology to achieve maximum impact for teacher learning; nevertheless, providing access alone is not sufficient to enhance teaching and learning. The geographical divide (urban / rural, district / national / regional) in access to 
technologies is well documented in research (e.g., ^Laurillard et al., 2018). Given the Covid-19 pandemic, ensuring access to technology is fundamental to enable the continuation of learning ( $\$$ Dreesen et al., 2020; ^Vegas, 2020).

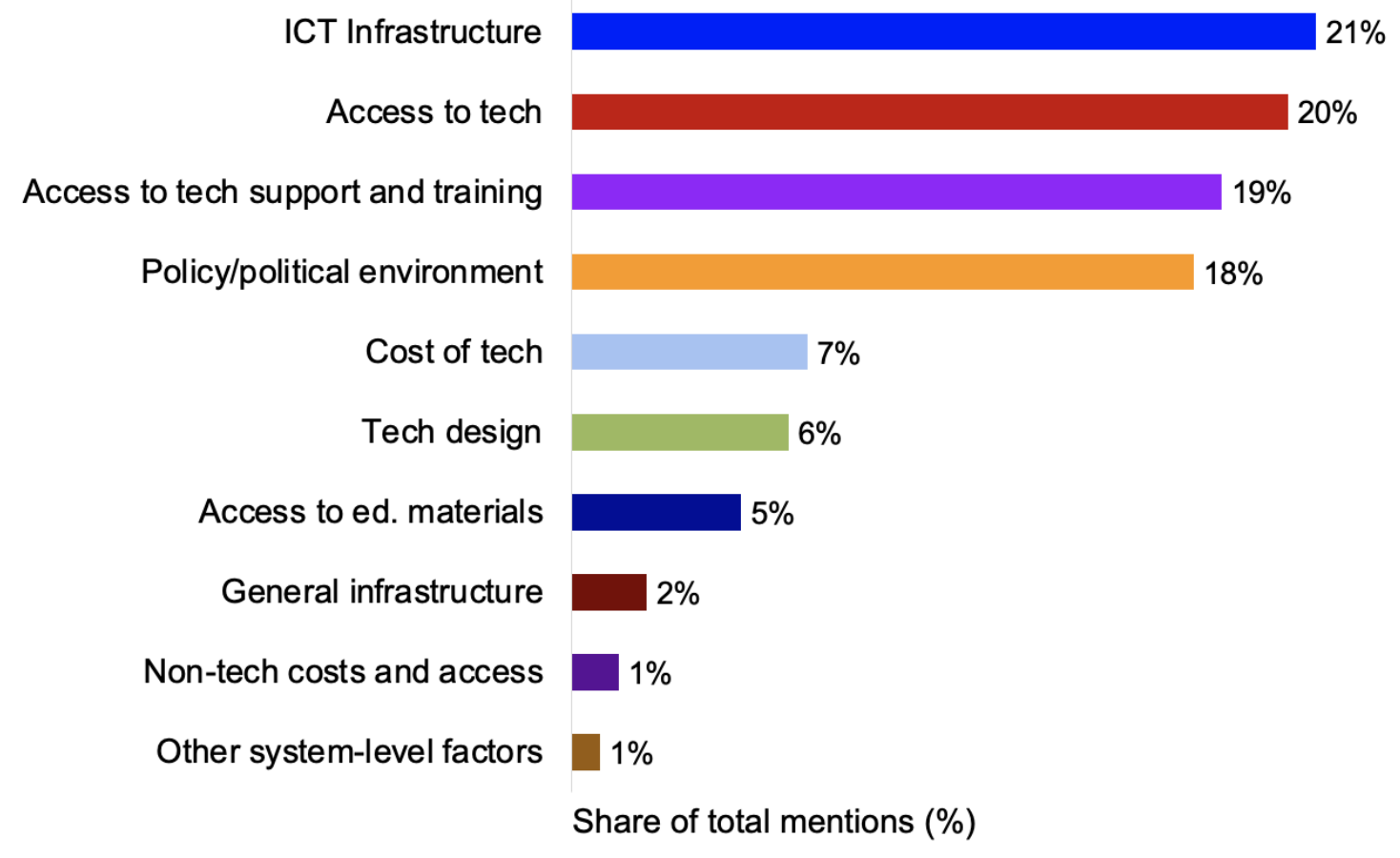

Figure 33. Contextual factors at the system level

\subsubsection{Contextual factors at local level}

At a local level, teacher's prior ICT skills (19\%) emerged to be the most frequently mentioned factor (Figure 34). We also found that adapting TPD to the local context (11\%), teachers' time constraints (10\%), teacher attitudes and beliefs (10\%), and leadership support were also prominent local-level factors for teacher learning through educational technology. Other local-level factors (15\%) included teacher incentives, teachers' prior subject / content knowledge, community support, class-level factors (e.g., student 
behaviour), learner interest, and student tech skills.

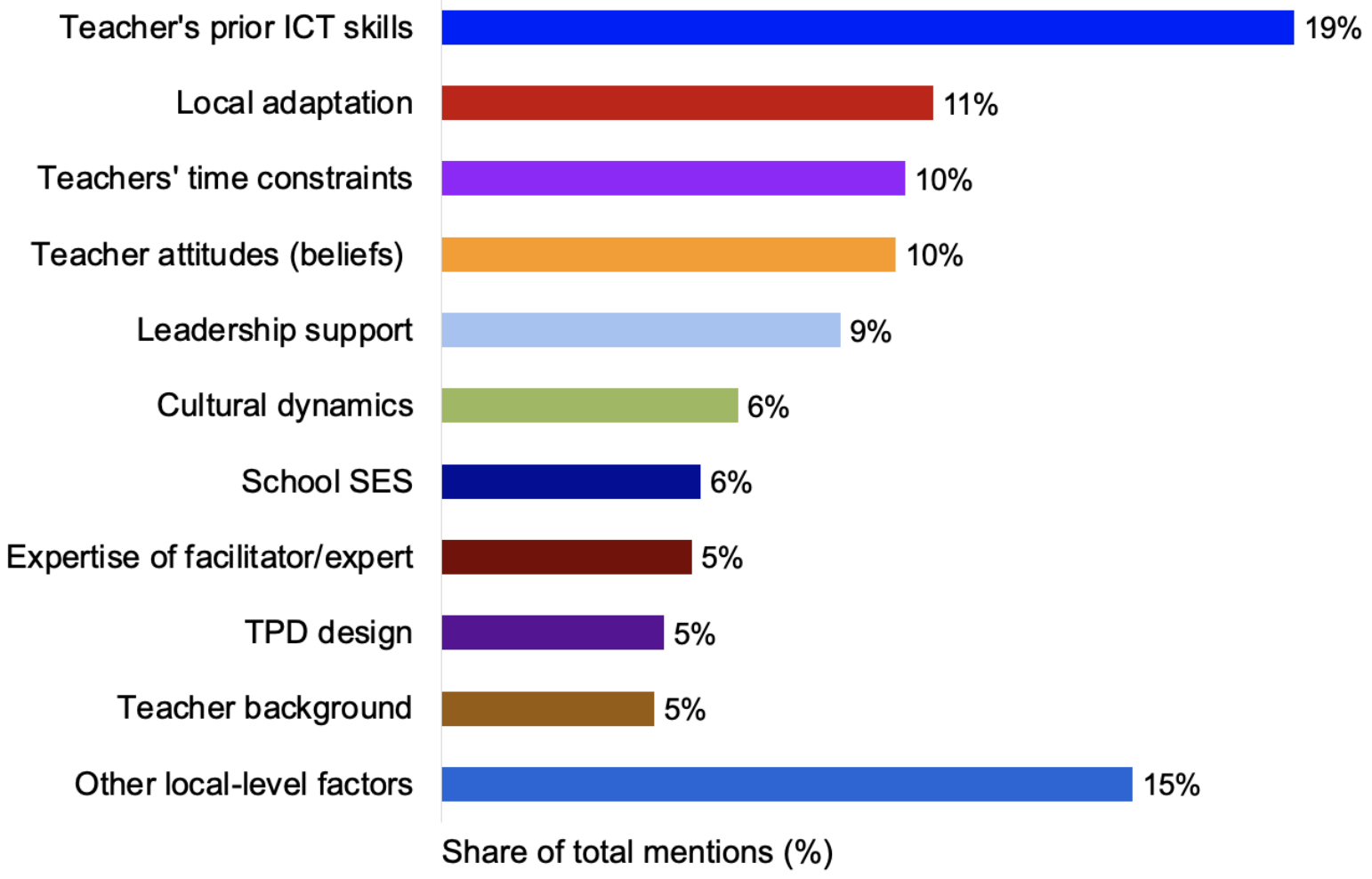

Figure 34. Contextual factors at the local level

\subsection{TPD for marginalised learners}

Few of the studies reviewed identified protected characteristics of target students of the teachers who participated in the TPD. Where reference was made to marginalisation, this was mainly in the context of socio-economic status ( $f=27$ ), followed by learners with disabilities ( $f=6)$, but even these characteristics of marginalisation were only mentioned in $8 \%$ and $2 \%$, respectively, of the studies reviewed. A disparate group of studies also focused on girls, children from remote communities, ethnic minorities, children living in conflict situations, and orphans (total $f=12$ ). Given the well-documented gender disparities relating to the access and use of technology - and the potential for EdTech to support learners for the most marginalised - the tiny number of studies focusing on TPD to improve teaching and learning for these groups of students was concerning. 


\section{Conclusion}

The proliferation in recent years of studies conducted in LMICs to examine the use of technology for TPD (RQ1), TPD supporting technology use in teaching, lesson planning, and assessment (RQ2), and TPD for supporting effective technology use by learners (RQ3) is a testimony to both the relevance and timeliness of this review. EdTech has the potential to foster more equitable education systems and provide enhanced learning opportunities for teachers and students in LMICs in general, and in remote and hard-to-reach communities in particular. When used effectively and adapted to local contexts, EdTech can be leveraged to overcome barriers specific to LMICs and those teachers and learners who are more often marginalised. As the results in Sections 4 and 5 of this report demonstrate, an array of technological devices and resources have been used in diverse ways, settings, and contexts. The TPD models in the studies reviewed have led to more collaborative professional learning and peer-to-peer support, developed teachers' pedagogical and content knowledge, helped teachers create resources in settings where there is otherwise a scarcity of such materials, and increased the motivation of teachers and learners alike. There is still an unanswered key question: What are the appropriate levels of support and structure needed for teachers in particular settings (and with particular characteristics) in LMICs, and how can EdTech be harnessed to most effectively contribute?

Across the 265 studies reviewed, various methodological and content-related evidence gaps become evident. First, there is an absence of voices of researchers from the LMICs (as stated in the limitations, and perhaps due to the focus on English language studies only). This may also be a contributing factor to the lack of geographical diversity of research. Nearly half of the studies reviewed (46\%) focused on six countries: Turkey $(n=52)$, South Africa $(n=22)$, Kenya ( $n=19)$, China $(n=17)$, Malaysia $(n=13)$, and India $(n=13)$. Four of these six countries are upper middle-income countries (Kenya and India being the only exceptions). This has implications for the generalisability of the findings for those countries that face the largest challenges to quality teaching. We therefore call for further research that incorporates Southern voices and spans more countries, especially LICs. Additionally, there was a surprisingly low number of studies that explicitly focused on TPD for unqualified teachers - the audience with the most potential for professional growth.

Given the context-specific nature of TPD, there was also an absence of ethnographic studies, and studies that used design-based research (two 
studies only for each). Because social, political, and material realities shape the effectiveness of TPD efforts ( $\uparrow$ Vavrus \& Bartlett, 2012), more studies are needed that foster co-creation with teachers and inquire into how their national, local, and individual identities inform how EdTech is used for TPD, teaching, and student learning. A final methodological gap in the reviewed studies concerns the issue of sustainability and effectiveness. There was a lack of longitudinal or follow-up studies that inquired into the long-term impacts of TPD programmes. Moreover, few studies measured changes in classroom practices or student learning, two outcomes that are most directly related to the quality education for which SDG 4 advocates.

Evidence gaps related to the content, design, and structure of TPD models paints a similar picture. There is a lacuna of studies on marginalised populations and communities. Only 13\% of the studies examined TPD programmes in remote and rural areas, and even fewer inquired into humanitarian contexts of conflict or fragility, despite the potential of EdTech to support teachers and learners in these settings ('Lawrie et al., 2015; 个Tauson \& Stannard, 2018). Similarly, few studies examined how TPD can support refugee and displaced learners, girls, or learners with disabilities - a finding that has been further confirmed by a recent EdTech Hub literature review ( $\$$ Lynch et al., 2027). It is surprising that marginalised learners and teachers were not often the focus of the studies, given the potential of EdTech to support their needs and address issues of equity (iLaurillard et al., 2018; 个Khan, 2018). Research indicates that the most privileged learners within each LMIC are the ones who often have access to technologies and thus benefit from their use ( Castillo et al., 2015; íliyanagunawardena et al., 2014; ^Selwyn, 2016). Our results illustrate the need for more research on the use of EdTech to improve teaching and learning for marginalised learners.

It is noteworthy that there were limited - though promising - examples of how technology can support the professional development of refugee teachers (^Bradley et al., 2019) and teachers with visual impairments (^Wormnaes \& Sellaeg, 2013). Although outliers in the review, these studies show promise, and more research that similarly focuses on the needs of marginalised teachers and learners is urgently needed if we are to continue fostering more equitable, quality, and culturally responsive education systems. 


\section{References}

Alexander, P. A. (2020). Methodological guidance paper: The art and science of quality systematic reviews. Review of Educational Research, 90(1), 6-23. https://doi.org/10/ggwsgp

Belotto, M. J. (2018). Data analysis methods for qualitative research: Managing the challenges of coding, interrater reliability, and thematic analysis. The Qualitative Report, 23(11), 2622-2633. https://doi.org/10.46743/2160-3715/2018.3492

Bradley, L., Bahous, R., \& Albasa, A. (2019). Mobile literacy among Syrian refugee women teachers. CALL and Complexity - Short Papers from EUROCALL 2019, 57-62. https://doi.org/10.14705/rpnet.2019.38.986

Castillo, N. M., Lee, J., Zahra, F. T., \& Wagner, D. A. (2015). MOOCs for development: Trends, challenges, and opportunities. Information Technologies \& International Development, 71(2), 35-42.

Cilliers, J., Fleischz, B., Kotzex, J., Mohohlwanex, N., Taylor, S., \& Thulare, T. (2020). Can virtual replace in-person coaching? Experimental evidence on teacher professional development and student learning. https://riseprogramme.org/sites/default/files/inline-files/Virtual\%20vs\%2 OlnPerson\%20Coaching\%20Working\%20Paper.pdf

Colandr. (2021). Colandr Community. Colandr Community. https://www.colandrcommunity.com/

DFID. (2018). DFID education policy: Get children learning. https://assets.publishing.service.gov.uk/government/uploads/system/upl oads/attachment_data/file/685536/DFID-Education-Policy-2018a.pdf

Dreesen, T., Akseer, S., Brossard, M., Dewan, P., Giraldo, J.-P., Kamei, A., Mizunoya, S., \& Ortiz, J. S. (2020). Promising practices for equitable remote learning: Emerging lessons from COVID-19 education responses in 727 countries (Innocenti Research Brief). UNICEF. https://www.unicef-irc.org/publications/1090-promising-practices-for-eq uitable-remote-learning-emerging-lessons-from-covid.html

Durusoy, O., \& Karamete, A. (2018). The effect of instructional material design process to mathematics teacher candidates' TPACK. European Journal of Education Studies, 4(5), 35-45. https://doi.org/10.5281/zenodo.1222082

Education Commission. (2019). Transforming the education workforce: Learning teams for a learning generation. Education Commission. https://educationcommission.org/transformingtheeducationworkforce/ 
Ekanayake, T. M. S. S. K. Y., \& Wishart, J. M. (2014). Developing teachers' pedagogical practice in teaching science lessons with mobile phones. Technology, Pedagogy \& Education, 23(2), 131-150. https://doi.org/10.1080/1475939X.2013.810366

Gloria, A., \& Oluwadara, A. (2016). Influence of mobile learning training on pre-service social studies teachers' technology and mobile phone self-efficacies. Journal of Education and Practice, 7(2), 74-79.

Grant, M. J., \& Booth, A. (2009). A typology of reviews: An analysis of 14 review types and associated methodologies. Health Information \& Libraries Journal, 26(2), 91-108.

https://doi.org/10.1111/j.1471-1842.2009.00848.x

Guskey, T. R. (2002). Does it make a difference? Evaluating professional development. Education Leadership, 59(6), 45-51.

Hennessy, S., D’Angelo, S., Mclntyre, N., Koomar, S., Kreimeia, A., Cao, L., Brugha, M., \& Zubairi, A. (Forthcoming). Technology use for teacher professional development in low- and middle-income countries: $A$ systematic review.

Hennessy, S., Haßler, B., \& Hofmann, R. (2016). Pedagogic change by Zambian primary school teachers participating in the OER4Schools professional development programme for one year. Research Papers in Education, 31(4), 399-427. https://doi.org/10.1080/02671522.2015.1073343

Hennessy, S., Jordan, K., Wagner, D. A., \& EdTech Hub Team. (2021). Problem analysis and focus of EdTech Hub's work: Technology in education in low- and middle-income countries. The EdTech Hub.

https://doi.org/10.5281/zenodo.4332693

Hinton, D. R., \& Robinson, M. (2015). Assessing the strength of evidence in the education sector. Building Evidence in Education.

https://www.usaid.gov/sites/default/files/documents/1865/BE2_Guidance _Note_ASE.pdf

Hong, Q. N., Pluye, P., Fabregues, S., Bartlett, G., Boardman, F., Cargo, M., Dagenais, P., Gagnon, M.-P., Griffiths, F., Nicolau, B., O'Cathain, A., Rousseau, M.-C., \& Vedel, I. (2018). Mixed methods appraisal tool (MMAT), version 2018 user guide. McGill University Department of Family Medicine.

http://mixed methodsappraisaltoolpublic.pbworks.com/w/file/fetch/12791 6259/MMAT_2018_criteria-manual_2018-08-01_ENG.pdf

Kaneko-Marques, S. M. (2015). Reflective teacher supervision through videos of classroom teaching (supervisión colaborativa docente a través de clases grabadas en video). PROFILE: Issues in Teachers' Professional Development, 17(2), 63-79. https://doi.org/10.15446/profile.v17n2.44393 
Khan, A. (2018). Pakistani teachers' professional learning experiences: Comparing face-to-face versus online learning. TEFLIN Journal, 29(1), 72-89. https://doi.org/10.15639/teflinjournal.v29i7/72-89

Kitchenham, B., Pearl Brereton, O., Budgen, D., Turner, M., Bailey, J., \& Linkman, S. (2009). Systematic literature reviews in software engineering-A systematic literature review. Information and Software Technology, 57(1), 7-15. https://doi.org/10.1016/j.infsof.2008.09.009

Laurillard, D., Kennedy, E., \& Wang, T. (2018). How could digital learning at scale address the issue of equity in education? (Learning at Scale for the Global South). Foundation for Information Technology Education and Development.

http://dl4d.org/wp-content/uploads/2019/03/Learning-at-Scale-for-the-C lobal-South-Main-Paper.pdf

Lawrie, J., Hennessy, S., Haßler, B., \& Phalachandra. (2015). Use ICT to provide access to content, professional development and professional learning communities (Recommendation 7). In M. Burns \& J. Lawrie (Eds.), Where it's needed most: Quality professional development for all teachers (pp. 131-143). Inter-Agency Network for Education in Emergencies (INEE).

https://inee.org/resources/where-its-needed-most-quality-professionaldevelopment-all-teachers

Liyanagunawardena, T., Williams, S., \& Adams, A. (2014). The impact and reach of MOOCs: A developing countries' perspective. ELearning Papers, 33, 38-46.

Lynch, P., Singhal, N., \& Francis, G. A. (2021). EdTech for learners with disabilities in primary school settings in LMICs: A systematic literature review. EdTech Hub. https://doi.org/10.5281/ZENODO.4348995

MacLean, R., \& Sen, K. (2019). Making a difference in the real world? A meta-analysis of the quality of use-oriented research using the Research Quality Plus approach. Research Evaluation, 28(2), 123-135. https://doi.org/10.1093/reseval/rvy026

Major, L., \& Francis, G. A. (2020). Technology-supported personalised learning: Rapid Evidence Review. EdTech Hub.

https://edtechhub.org/wp-content/uploads/2020/09/Rapid-Evidence-Re view_-Technology-supported-personalised-learning.pdf

Major, L., \& Watson, S. (2017). Using video to support in-service teacher professional development: The state of the field, limitations and possibilities. Technology, Pedagogy \& Education, 27(1), 49-68. https://doi.org/10.1080/1475939X.2017.1361469

McAleavy, T., Hall-Chen, A., Horrocks, S., \& Riggall, A. (2018). Technology-supported professional development for teachers: Lessons 
from developing countries. In Education Development Trust. Education Development Trust.

https://www.educationdevelopmenttrust.com/our-research-and-insight s/research/technology-supported-professional-development-for-

McEwan, P. J. (2015). Improving learning in primary schools of developing countries: A meta-analysis of randomized experiments. Review of Educational Research, 85(3), 353-394. https://doi.org/10.3102/0034654314553127

Moher, D., Liberati, A., Tetzlaff, J., \& Altman, D. G. (2009). Preferred reporting items for systematic reviews and meta-analyses: The PRISMA statement. British Medical Journal. https://doi.org/10.1136/bmj.b2535

Piper, B., Oyanga, A., Mejia, J., \& Pouezevara, S. (2017). Implementing large-scale instructional technology in Kenya: Changing instructional practice and developing accountability in a national education system. International Journal of Education and Development Using Information and Communication Technology, 13(3), 57-79.

Qasem, A. A. A., \& Viswanathappa, G. (2016). Blended learning approach to develop the teachers' TPACK. Contemporary Educational Technology, 7(3), 264-276. https://doi.org/10.30935/cedtech/6176

School-to-School International (STS). (2017). GraphoGame Teacher Training Service: Evaluation report. Agora Center, University of Jyväskylä, Finland.

https://allchildrenreading.org/wp-content/uploads/2019/07/Agora-Cente r-Project-Evaluation.pdf

SDG-Education 2030 Steering Committee. (n.d.). Sustainable Development Goal 4 (SDG 4) | Education within the 2030 Agenda for Sustainable Development. Retrieved 18 September 2020, from https://sdg4education2030.org/the-goal

Selwyn, N. (2016). Is technology good for education? Polity Press. https://bit.ly/3r82ePY

Shohel, M. M. C., \& Power, T. (2010). Introducing mobile technology for enhancing teaching and learning in Bangladesh: Teacher perspectives. Open Learning: The Journal of Open, Distance and e-Learning, 25(3), 201-215. https://doi.org/10.1080/02680513.2010.511953

Slade, T. S., Kipp, S., Cummings, S., \& Nyirongo, K. (2018). Short message service (SMS)-based remote support and teacher retention of training gains in Malawi. In S. Pouezevara (Ed.), Cultivating dynamic educators: Case studies in teacher behavior change in Africa and Asia (pp. 131-167). RTI Press. https://bit.ly/3r82ePY 
Tauson, M., \& Stannard, L. (2018). EdTech for learning in emergencies and displaced settings - A rigorous review and narrative synthesis. Save the Children.

https://www.savethechildren.org.uk/content/dam/global/reports/educati on-and-child-protection/edtech-learning.pdf

Teachers' Research Exchange. (2021). The Teachers' Research Exchange (T-REX): Connecting Teaching, Research and Practice in Initial Teacher Education. National Forum for the Enhancement of Teaching and Learning in Higher Education.

https://www.teachingandlearning.ie/project/the-teachers-research-exch ange-t-rex-connecting-teaching-research-and-practice-in-initial-teache r-education/

Twining, P., Raffaghelli, J., Albion, P., \& Knezek, D. (2013). Moving education into the digital age: The contribution of teachers' professional development. Journal of Computer Assisted Learning, 29(5), 426-437. https://doi.org/10.1111/jcal.12031

UIS. (2019). UIS Statistics [UNESCO Institute for Statistics (UIS)]. http://data.uis.unesco.org/

Vavrus, F., \& Bartlett, L. (2012). Comparative pedagogies and epistemological diversity: Social and materials contexts of teaching in Tanzania. Comparative Education Review, 56(4), 634-658. https://doi.org/10.1086/667395

Vegas, E. (2020). School closures, government responses, and learning inequality around the world during COVID-19. The Brookings Institution.

https://www.brookings.edu/research/school-closures-government-respo nses-and-learning-inequality-around-the-world-during-covid-19/

Waddington, H., White, H., Snilstveit, B., Hombrados, J. G., Vojtkova, M., Davies, P., Bhavsar, A., Eyers, J., Koehlmoos, T. P., Petticrew, M., Valentine, J. C., \& Tugwell, P. (2012). How to do a good systematic review of effects in international development: A tool kit. Journal of Development Effectiveness, 4(3), 359-387. https://doi.org/10.1080/19439342.2012.711765

World Bank. (2018). World Development Report 2018: Learning to realize education's promise.

https://openknowledge.worldbank.org/handle/10986/28340

World Bank. (2021). World Bank Country and Lending Groups - World Bank Data Help Desk.

https://datahelpdesk.worldbank.org/knowledgebase/articles/906519-wor Id-bank-country-and-lending-groups 
Wormnaes, S., \& Sellaeg, N. (2013). Audio-described educational materials: Ugandan teachers' experiences. British Journal of Visual Impairment, 31(2), 164-171. https://doi.org/10.1177/0264619613485029 


\section{Supplementary material}

Technology and TPD in LMICs - Full literature database 


\section{Appendices}

\section{Appendix A. Low- and middle-income countries included in searches}

Countries searched for were as follows:

Afghanistan; Albania; Algeria; American Samoa; Angola; Argentina; Armenia; Azerbaijan; Bangladesh; Belarus; Belize; Benin; Bhutan; Bolivia; Bosnia and Herzegovina; Botswana; Brazil; Bulgaria; Burkina Faso; Burundi; Cabo Verde; Cambodia; Cameroon; Central African Republic; Chad; China; Colombia; Comoros; Congo, Dem. Rep.; Congo, Rep.; Costa Rica; Côte d'Ivoire; ; Cuba; Djibouti; Dominica; Dominican Republic; Ecuador; Egypt, Arab Rep.; El Salvador; Equatorial Guinea; Eritrea; Eswatini; Ethiopia; Fiji; Gabon; Gambia, The; Georgia; Ghana; Grenada; Guatemala; Guinea; Guinea-Bissau; Guyana; Haiti; Honduras; India; Indonesia; Iran, Islamic Rep.; Iraq; Jamaica; Jordan; Kazakhstan; Kenya; Kiribati; Korea, Dem. People's Rep.; Kosovo; Kyrgyz Republic; Lao PDR; Lebanon; Lesotho; Liberia; Libya; Madagascar; Malawi; Malaysia; Maldives; Mali; Marshall Islands; Mauritania; Mexico; Micronesia, Fed. Sts.; Moldova; Mongolia; Montenegro; Morocco; Mozambique; Myanmar; Namibia; Nepal; Nicaragua; Niger; Nigeria; North Macedonia; Pakistan; Papua New Guinea; Paraguay; Peru; Philippines; Russian Federation; Rwanda; Samoa; Sao Tome and Principe; Senegal; Serbia; Sierra Leone; Solomon Islands; Somalia; South Africa; South Sudan; Sri Lanka; St. Lucia; St. Vincent and the Grenadines; Sudan; Suriname; Syrian Arab Republic; Tajikistan; Tanzania; Thailand; Timor-Leste; Togo; Tonga; Tunisia; Turkey; Turkmenistan; Tuvalu; Uganda; Ukraine; Uzbekistan; Vanuatu; Venezuela, RB; Vietnam; West Bank and Gaza; Yemen, Rep.; Zambia; Zimbabwe

This list of 136 countries derives from the World Bank's (2020) country inventory ( $\uparrow$ World Bank, 2021).

\section{Appendix B. Data extraction variables}

Click on the paperclip icon in the left-hand panel to open the attachment for Appendix B

\section{Appendix C. Thematic coding scheme with RQ1-RQ3 frequencies}

Click on the paperclip icon in the left-hand panel to open the attachment for Appendix C 


\section{Appendix D. Research quality scoring framework}

Click on the paperclip icon in the left-hand panel to open the attachment for Appendix D

\section{Appendix E. Number of studies by country}

$\begin{array}{llllll}\text { Country } & \begin{array}{l}\text { Country income } \\ \text { level }\end{array} & \begin{array}{l}\text { Total number } \\ \text { of studies }\end{array} & \text { RQ1 } & \text { RQ2 } & \text { RQ3 }\end{array}$

$\begin{array}{llllll}\text { Afghanistan } & \text { Low income } & 1 & 1 & 0 & 0\end{array}$

\begin{tabular}{|c|c|c|c|c|c|}
\hline Bangladesh & $\begin{array}{l}\text { Lower middle } \\
\text { income }\end{array}$ & 9 & 8 & 2 & 2 \\
\hline Benin & $\begin{array}{l}\text { Lower middle } \\
\text { income }\end{array}$ & 1 & 1 & 0 & 0 \\
\hline Bolivia & $\begin{array}{l}\text { Lower middle } \\
\text { income }\end{array}$ & 1 & 1 & 0 & 1 \\
\hline Brazil & $\begin{array}{l}\text { Upper middle } \\
\text { income }\end{array}$ & 8 & 4 & 3 & 4 \\
\hline Burkina Faso & Low income & 1 & 0 & 1 & 0 \\
\hline Cambodia & $\begin{array}{l}\text { Lower middle } \\
\text { income }\end{array}$ & 1 & 1 & 0 & 0 \\
\hline Cameroon & $\begin{array}{l}\text { Lower middle } \\
\text { income }\end{array}$ & 1 & 0 & 1 & 0 \\
\hline China & $\begin{array}{l}\text { Upper middle } \\
\text { income }\end{array}$ & 17 & 10 & 5 & 4 \\
\hline Colombia & $\begin{array}{l}\text { Upper middle } \\
\text { income }\end{array}$ & 2 & 1 & 1 & 1 \\
\hline
\end{tabular}




\begin{tabular}{|c|c|c|c|c|c|}
\hline $\begin{array}{l}\text { Dominican } \\
\text { Republic }\end{array}$ & $\begin{array}{l}\text { Upper middle } \\
\text { income }\end{array}$ & 1 & 1 & 0 & 0 \\
\hline Ecuador & $\begin{array}{l}\text { Upper middle } \\
\text { income }\end{array}$ & 1 & 1 & 1 & 0 \\
\hline $\begin{array}{l}\text { Egypt, Arab } \\
\text { Rep. }\end{array}$ & $\begin{array}{l}\text { Lower middle } \\
\text { income }\end{array}$ & 2 & 1 & 1 & 0 \\
\hline Ethiopia & Low income & 3 & 1 & 2 & 0 \\
\hline Ghana & $\begin{array}{l}\text { Lower middle } \\
\text { income }\end{array}$ & 9 & 5 & 7 & 1 \\
\hline India & $\begin{array}{l}\text { Lower middle } \\
\text { income }\end{array}$ & 11 & 10 & 7 & 5 \\
\hline Indonesia & $\begin{array}{l}\text { Upper middle } \\
\text { income }\end{array}$ & 9 & 8 & 2 & 0 \\
\hline $\begin{array}{l}\text { Iran, Islamic } \\
\text { Rep. }\end{array}$ & $\begin{array}{l}\text { Upper middle } \\
\text { income }\end{array}$ & 3 & 2 & 1 & 0 \\
\hline Jamaica & $\begin{array}{l}\text { Upper middle } \\
\text { income }\end{array}$ & 1 & 0 & 0 & 1 \\
\hline Jordan & $\begin{array}{l}\text { Upper middle } \\
\text { income }\end{array}$ & 2 & 0 & 2 & 0 \\
\hline Kazakhstan & $\begin{array}{l}\text { Upper middle } \\
\text { income }\end{array}$ & 1 & 1 & 0 & 0 \\
\hline Kenya & $\begin{array}{l}\text { Lower middle } \\
\text { income }\end{array}$ & 20 & 14 & 8 & 5 \\
\hline Lebanon & $\begin{array}{l}\text { Upper middle } \\
\text { income }\end{array}$ & 3 & 2 & 1 & 0 \\
\hline
\end{tabular}




\begin{tabular}{|c|c|c|c|c|c|}
\hline Malawi & Low income & 5 & 3 & 2 & 0 \\
\hline Malaysia & $\begin{array}{l}\text { Upper middle } \\
\text { income }\end{array}$ & 13 & 7 & 5 & 2 \\
\hline Mexico & $\begin{array}{l}\text { Upper middle } \\
\text { income }\end{array}$ & 5 & 3 & 1 & 2 \\
\hline Mongolia & $\begin{array}{l}\text { Lower middle } \\
\text { income }\end{array}$ & 1 & 0 & 1 & 0 \\
\hline Mozambique & Low income & 1 & 1 & 0 & 0 \\
\hline Namibia & $\begin{array}{l}\text { Upper middle } \\
\text { income }\end{array}$ & 1 & 1 & 0 & 0 \\
\hline Nepal & $\begin{array}{l}\text { Lower middle } \\
\text { income }\end{array}$ & 4 & 3 & 2 & 1 \\
\hline Nicaragua & $\begin{array}{l}\text { Lower middle } \\
\text { income }\end{array}$ & 1 & 1 & 0 & 0 \\
\hline Nigeria & $\begin{array}{l}\text { Lower middle } \\
\text { income }\end{array}$ & 6 & 5 & 2 & $\mathrm{O}$ \\
\hline Pakistan & $\begin{array}{l}\text { Lower middle } \\
\text { income }\end{array}$ & 6 & 5 & 1 & 1 \\
\hline Peru & $\begin{array}{l}\text { Upper middle } \\
\text { income }\end{array}$ & 1 & 0 & 1 & 1 \\
\hline Philippines & $\begin{array}{l}\text { Lower middle } \\
\text { income }\end{array}$ & 2 & 0 & 1 & 2 \\
\hline Rwanda & Low income & 3 & 2 & 1 & 1 \\
\hline $\begin{array}{l}\text { São Tomé and } \\
\text { Príncipe }\end{array}$ & $\begin{array}{l}\text { Lower middle } \\
\text { income }\end{array}$ & 1 & 0 & 1 & 0 \\
\hline
\end{tabular}


Lower middle

Senegal

income

1

$\begin{array}{lll}0 & 1 & 1\end{array}$

\begin{tabular}{|c|c|c|c|c|c|}
\hline South Africa & $\begin{array}{l}\text { Upper middle } \\
\text { income }\end{array}$ & 22 & 13 & 10 & 8 \\
\hline Sri Lanka & $\begin{array}{l}\text { Lower middle } \\
\text { income }\end{array}$ & 6 & 2 & 3 & 2 \\
\hline $\begin{array}{l}\text { Syrian Arab } \\
\text { Republic }\end{array}$ & Low income & 1 & 0 & 1 & 0 \\
\hline Tanzania & $\begin{array}{l}\text { Lower middle } \\
\text { income }\end{array}$ & 8 & 6 & 7 & 2 \\
\hline Thailand & $\begin{array}{l}\text { Upper middle } \\
\text { income }\end{array}$ & 3 & 3 & 0 & 1 \\
\hline Tunisia & $\begin{array}{l}\text { Lower middle } \\
\text { income }\end{array}$ & 2 & 1 & 2 & 0 \\
\hline Turkey & $\begin{array}{l}\text { Upper middle } \\
\text { income }\end{array}$ & 52 & 31 & 18 & 6 \\
\hline Uganda & Low income & 6 & 4 & 3 & 0 \\
\hline Vietnam & $\begin{array}{l}\text { Lower middle } \\
\text { income }\end{array}$ & 4 & 4 & 1 & 0 \\
\hline Yemen, Rep. & Low income & 2 & 1 & 1 & 0 \\
\hline Zambia & $\begin{array}{l}\text { Lower middle } \\
\text { income }\end{array}$ & 6 & 3 & 5 & 2 \\
\hline Zimbabwe & $\begin{array}{l}\text { Lower middle } \\
\text { income }\end{array}$ & 1 & 1 & 0 & 0 \\
\hline
\end{tabular}




\section{Appendix F. Number of studies by country income level}

\begin{tabular}{ll} 
Country income level & Number of studies \\
\hline Low income & 23 \\
\hline Lower middle income & 104 \\
\hline Upper middle income & 145 \\
\hline
\end{tabular}

Note: the total number of studies exceeded 265 as one study could contain multiple countries. 